\title{
Mitochondria-targeted Sensor Array with Aggregation-induced Emission Luminogens for Identification of Various cells
}

Yufan Ma, a Wenting Ai, a Jia Huang, ${ }^{b}$ Lijun Ma, a Yujie Geng, ${ }^{a}$ Xiaolei Liu, ${ }^{b}$ Xuefei Wang, c*

Zhiying Yang, ${ }^{\text {b* }}$ and Zhuo Wang ${ }^{\text {a* }}$

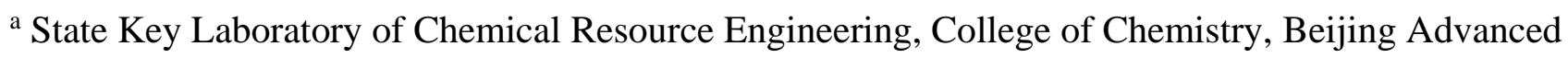
Innovation Centre for Soft Matter Science and Engineering, Beijing University of Chemical Technology, Beijing, 100029, China.

${ }^{b}$ A Department of General Surgery, China-Japan Friendship Hospital, Beijing 100029, China.

${ }^{c}$ School of Chemistry and Chemical Engineering, University of Chinese Academy of Sciences, Beijing, 100049, China.

*Corresponding author:

Zhuo Wang; E-mail: wangzhuo77@mail.buct.edu.cn

Zhiying Yang; E-mail: yangzhy@aliyun.com

Xuefei Wang; E-mail: wangxf@ucas.ac.cn 


\section{Table of Contents}

Scheme S1 The synthetic routes of PT1.

Scheme S2 The synthetic routes of PT3.

Scheme S3 The synthetic routes of PT4.

Figure $\mathbf{S 1}{ }^{1} \mathrm{H}$ NMR spectrum of TPE-2OH in DMSO-d 6 .

Figure S2 ${ }^{13} \mathrm{C}$ NMR spectrum of TPE-2OH in DMSO-d6.

Figure S3 HRMS spectrum of TPE-2OH.

Figure S4 ${ }^{1} \mathrm{H}$ NMR spectrum of TPE- $2 \mathrm{OC}_{3} \mathrm{Br}$ in Chloroform-d.

Figure S5 ${ }^{13} \mathrm{C}$ NMR spectrum of TPE- $2 \mathrm{OC}_{3} \mathrm{Br}$ in Chloroform-d.

Figure S6 HRMS spectrum of TPE- $2 \mathrm{OC}_{3} \mathrm{Br}$.

Figure S7 ${ }^{1} \mathrm{H}$ NMR spectrum of PT1 in Chloroform-d.

Figure S8 ${ }^{13} \mathrm{C}$ spectrum of PT1 in Chloroform-d.

Figure S9 HRMS spectrum of PT1.

Figure S10 ${ }^{1} \mathrm{H}$ NMR spectrum of PT2 in methanol-d 4 .

Figure S11 ${ }^{13} \mathrm{C}$ NMR spectrum of PT2 in methanol-d 4 .

Figure S12 HRMS spectrum of PT2.

Figure S13 ${ }^{1} \mathrm{H}$ NMR spectrum of PT3 in DMSO-d 6.

Figure S14 ${ }^{13} \mathrm{C}$ NMR spectrum of PT3 in DMSO-d6.

Figure S15 HRMS spectrum of PT3.

Figure S16 ${ }^{1} \mathrm{H}$ NMR spectrum of PT4 in Chloroform-d.

Figure S17 ${ }^{13} \mathrm{C}$ NMR spectrum of PT4 in Chloroform-d.

Figure S18 HRMS spectrum of PT4.

Figure S19 The absorption spectra of PTx in 65\% glycerol solution.

Figure S20 Fluorescence intensity spectra of PTx in glycerol aqueous solution with different glycerol fraction $\left(\mathrm{f}_{\mathrm{G}}\right)$.

Figure S21 Fluorescence intensity spectra of PTx with various concentration of BSA.

Figure S22 The normalized fluorescence intensity of PTx $(x=3,4,5)$ in different cells.

Figure S23 Cytotoxicity of PTx evaluated on HeLa cells.

Figure S24 Confocal fluorescence images of seven kinds of different cells stain with PTx.

Figure S25 Confocal fluorescence images of four kinds of gastric cells stain with PTx.

Figure S26 The minimum detectable cell concentration of the PTx-Sa.

Figure S27 Schematic diagram of the contribution of the probes to the main components in the sensor array in digestive tract cancer cells.

Table S1 Properties of PTx.

Table S2 SVM results for identification of unknown samples within the reference set for seven different cells using PTx-Sa.

Table S3 SVM results for identification of unknown samples within the reference set for four different digestive tract cell lines using PTx-Sa.

Table S4 SVM results for identification of unknown samples within the reference set for four different gastric cell lines using PTx-Sa.

Table S5 SVM results for identification of unknown samples within the reference set for mixed gastric cell lines using PTx-Sa.

Table S6 SVM results for identification of unknown samples within the reference set for seven different cells using PT2, PT3 and PT5.

Table S7 SVM results for identification of unknown samples within the reference set for seven different cells using PT2 and PT3. 


\section{Synthesis and characterization}

The synthesis steps of PT2, TPE-2CHO and PT5 has been published in previous literature. ${ }^{[1-2]}$
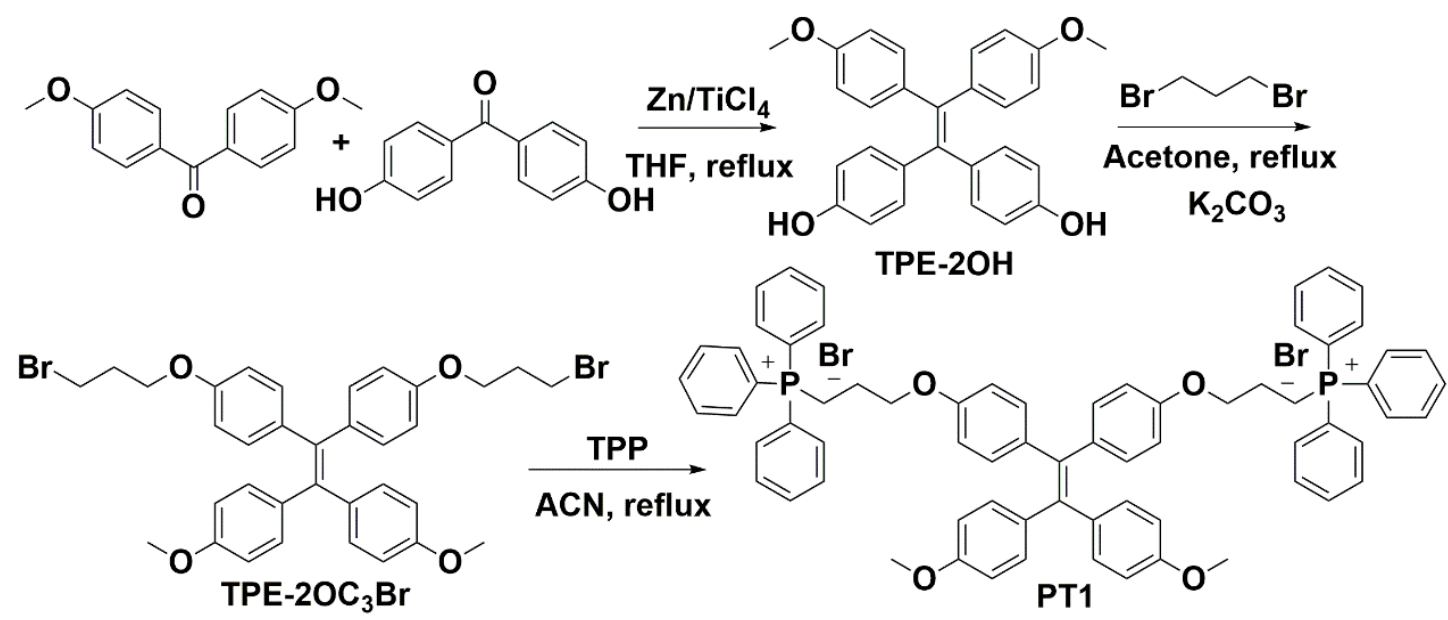

Scheme S1 The synthetic routes of PT1.

Synthesis of TPE-2OH. Dry THF $(150 \mathrm{~mL})$ was added to the mixture of 4,4'Dihydroxybenzophenone (3.00 g, $14 \mathrm{mmol}), 4$, '-Dimethoxybenzophenone (3.39 g, $14 \mathrm{mmol})$ and zinc dusk $(7.28 \mathrm{~g}, 112 \mathrm{mmol})$ and stored at $0^{\circ} \mathrm{C}$ under $\mathrm{N}_{2}$. Titanium tetrachloride $(6.15 \mathrm{~mL}, 56$ mmol) was added to the cold mixture and stirred at $0^{\circ} \mathrm{C}$ for $0.5 \mathrm{~h}$, then refluxed for $9 \mathrm{~h}$. Saturated potassium carbonate solution was added to the mixture to quench titanium tetrachloride. Filtering to remove zinc powder, the solution extracted with water and dichloromethane (DCM) (100 $\mathrm{mL}^{*} 3$ ). The organic phase was collected, washed with water and then dried over by anhydrous sodium sulfate. The product was purified with chromatography using the eluent of petroleum ether/ethylacetate (4: 1, v/v) to get a white solid (3.38 g, yield: 57\%). ${ }^{1} \mathrm{H}$ NMR (400 MHz, DMSOd6) $\delta 9.27(\mathrm{~s}, 2 \mathrm{H}), 6.84(\mathrm{~d}, J=8.5 \mathrm{~Hz}, 4 \mathrm{H}), 6.74(\mathrm{~d}, J=8.3 \mathrm{~Hz}, 4 \mathrm{H}), 6.68(\mathrm{~d}, J=8.5 \mathrm{~Hz}, 4 \mathrm{H}), 6.50$ (d, $J=8.5 \mathrm{~Hz}, 4 \mathrm{H}), 3.68$ (s, 6H). ${ }^{13} \mathrm{C}$ NMR (100 MHz, DMSO-d $) \delta 157.23,155.51,138.74$, $136.88,136.56,134.69,131.93,114.54,113.06,54.83$. HR-MS (MALDI-TOF) calcd for $\mathrm{C}_{28} \mathrm{H}_{24} \mathrm{O}_{4}\left[\mathrm{M}^{+}\right] 424.17$, found 424.1672

Synthesis of TPE-2OC $3 \mathbf{B r}$. Dry acetone was added to the mixture of TPE-2OH $(1.00 \mathrm{~g}, 2.36 \mathrm{mmol})$, 1,3-dibromopropane $(1.65 \mathrm{~mL}, 11.8 \mathrm{mmol})$ and $\mathrm{K}_{2} \mathrm{CO}_{3}(0.98 \mathrm{~g}, 7.07 \mathrm{mmol})$, then refluxed for 48 h. Cooled down to room temperature and extracted with water and DCM $(20 \mathrm{~mL} * 3)$. After dried over by anhydrous sodium sulfate, the organic phase was purified with chromatography using the eluent of petroleum ether/ethylacetate $(10: 1, \mathrm{v} / \mathrm{v})$ to get a white solid $(1.13 \mathrm{~g}$, yield: $72 \%) .{ }^{1} \mathrm{H}$ NMR (400 MHz, Chloroform-d) $\delta 7.03-6.87(\mathrm{~m}, 8 \mathrm{H}), 6.67$ (dd, $J=8.8,3.0 \mathrm{~Hz}, 8 \mathrm{H}), 4.06(\mathrm{t}, J=$ $5.8 \mathrm{~Hz}, 4 \mathrm{H}), 3.78(\mathrm{~s}, 6 \mathrm{H}), 3.61(\mathrm{t}, J=6.4 \mathrm{~Hz}, 4 \mathrm{H}), 2.31(\mathrm{p}, J=6.1 \mathrm{~Hz}, 4 \mathrm{H}) .{ }^{13} \mathrm{C}$ NMR $(100 \mathrm{MHz}$, Chloroform-d) $\delta 157.83,156.92,137.15,136.84,132.55,113.64,113.05,65.14,55.11,32.51$, 30.11. HR-MS (MALDI-TOF) calcd for $\mathrm{C}_{34} \mathrm{H}_{34} \mathrm{Br}_{2} \mathrm{O}_{4}[\mathrm{M}+2 \mathrm{H}]^{+} 666.08$, found 666.0797 


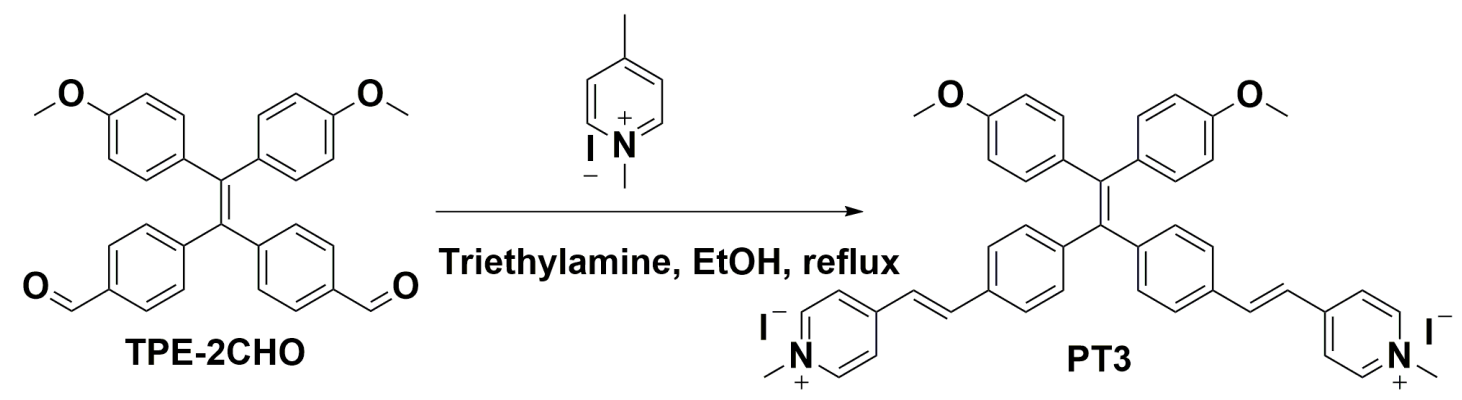

Scheme S2 The synthetic routes of PT3.

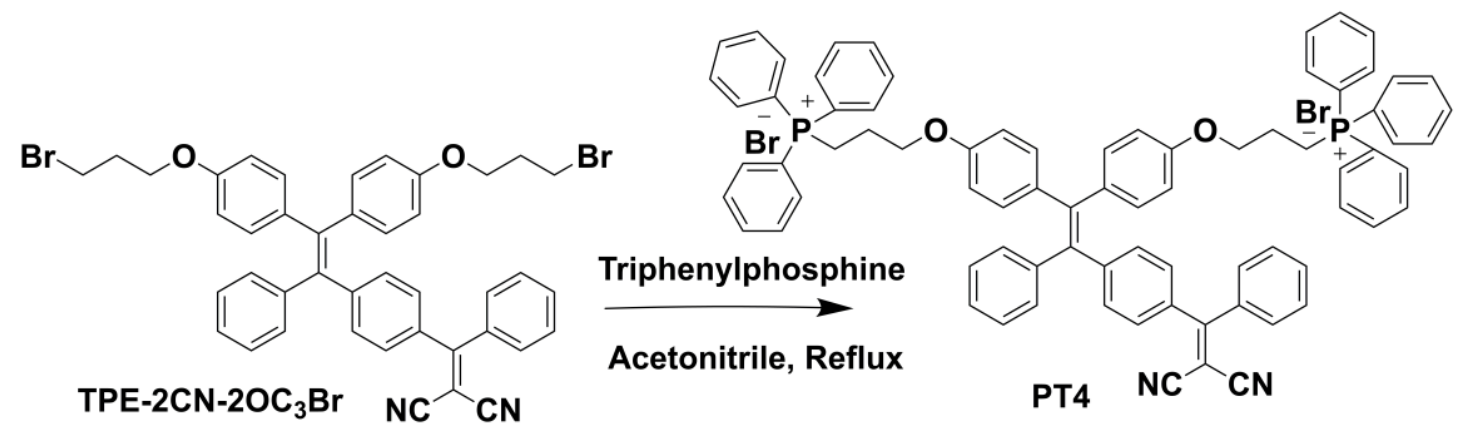

Scheme S3 The synthetic routes of PT4.

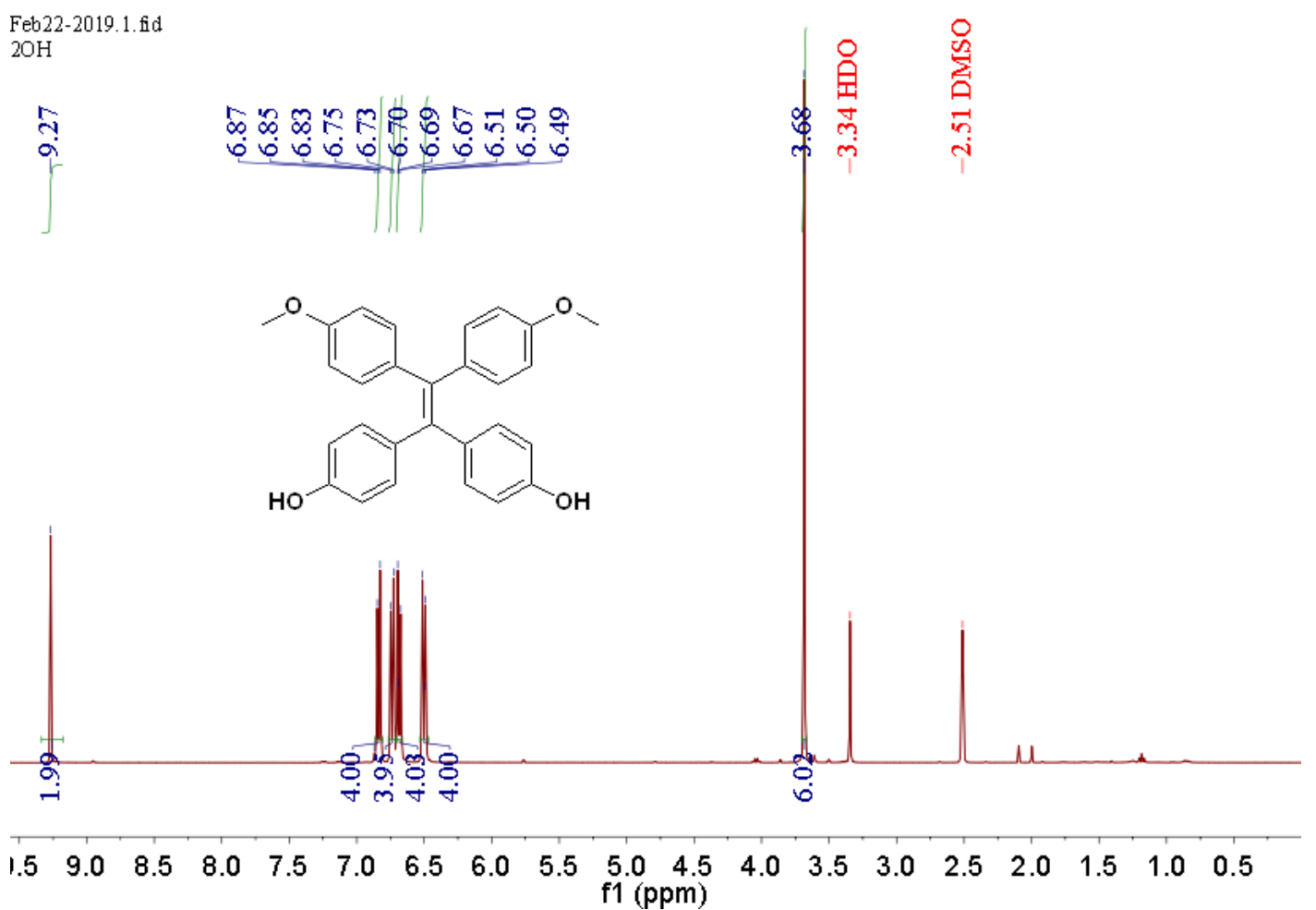

Figure S1 ${ }^{1} \mathrm{H}$ NMR spectrum of TPE-2OH in DMSO-d6. 
Feb22-2019.2.fid

$2 \mathrm{OH}$

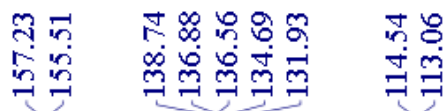

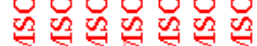

台台台占台台台<smiles>COc1ccc(C(=C(c2ccc(O)cc2)c2ccc(O)cc2)c2ccc(OC)cc2)cc1</smiles>

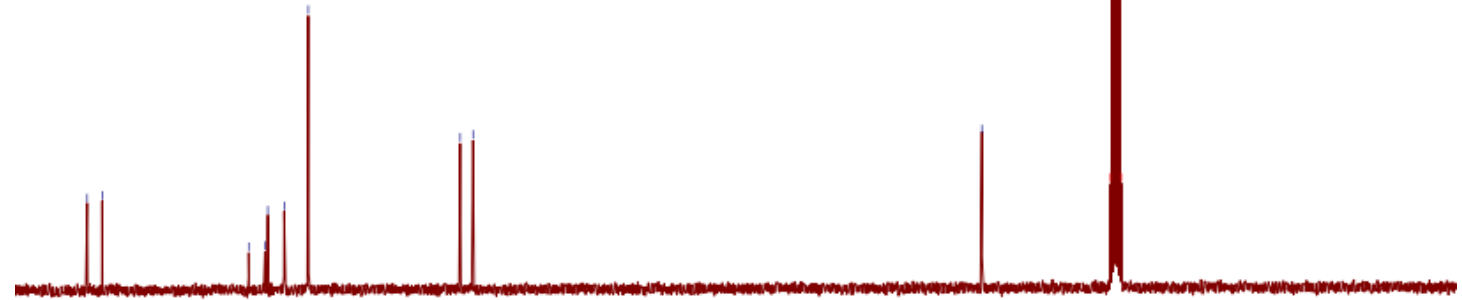

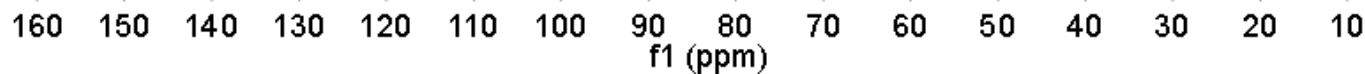

Figure S2 ${ }^{13} \mathrm{C}$ NMR spectrum of TPE-2OH in DMSO-d 6 .

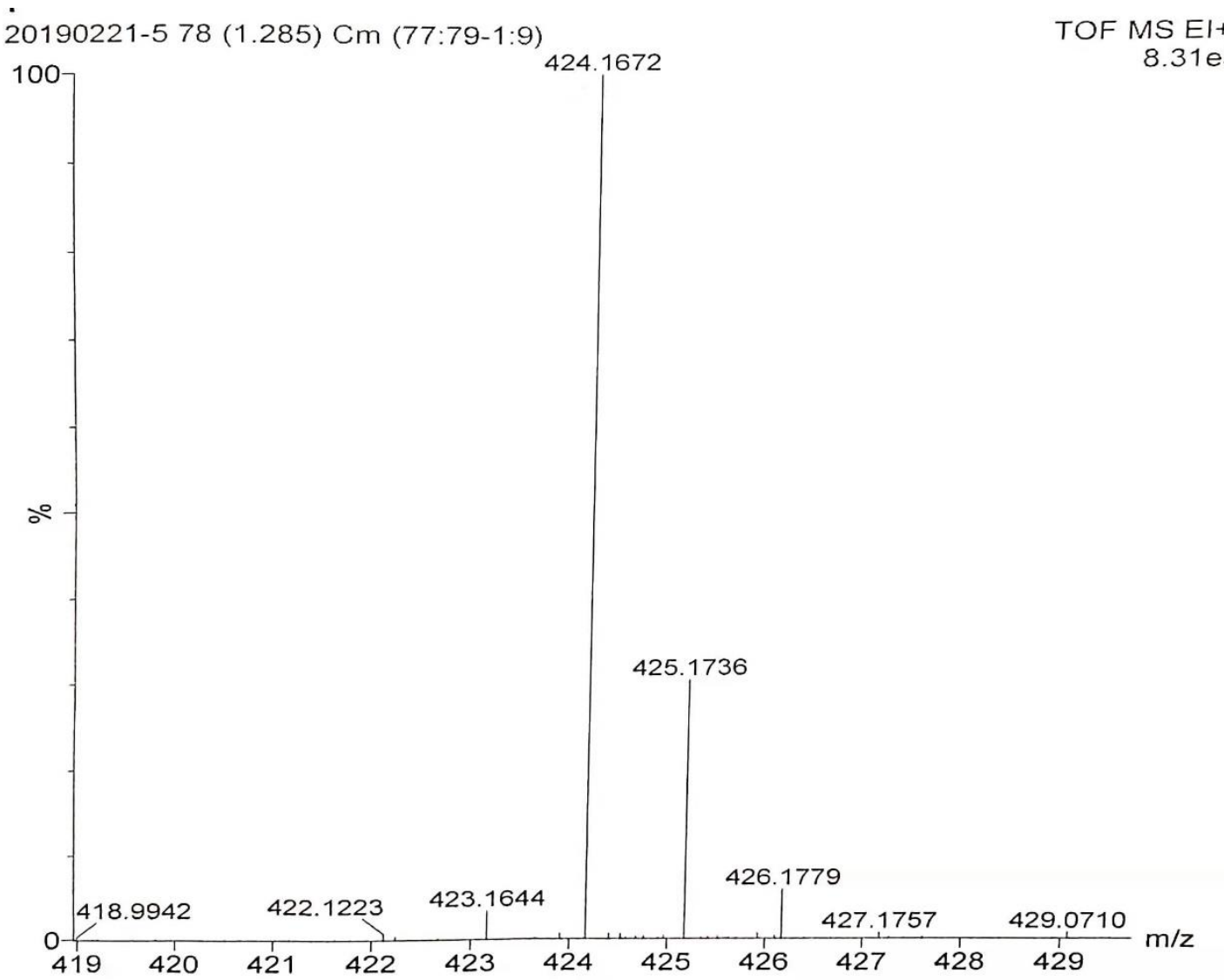

Figure S3 HRMS spectrum of TPE-2OH. 
<smiles>COc1ccc(C(=C(c2ccc(OC)cc2)c2ccc(OCCCBr)cc2)c2ccc(OCCCBr)cc2)cc1</smiles>
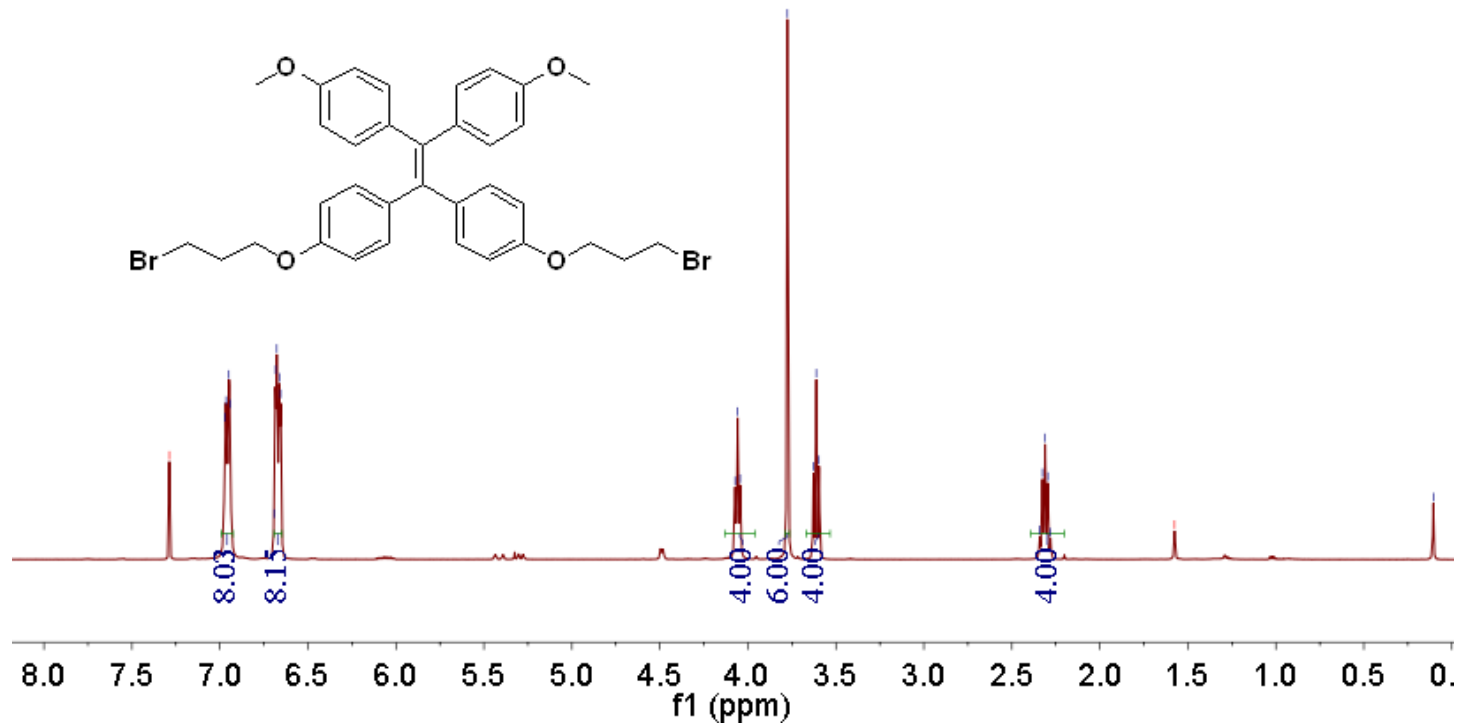

Figure S4 ${ }^{1} \mathrm{H}$ NMR spectrum of TPE-2OC 33 Br in Chloroform-d.

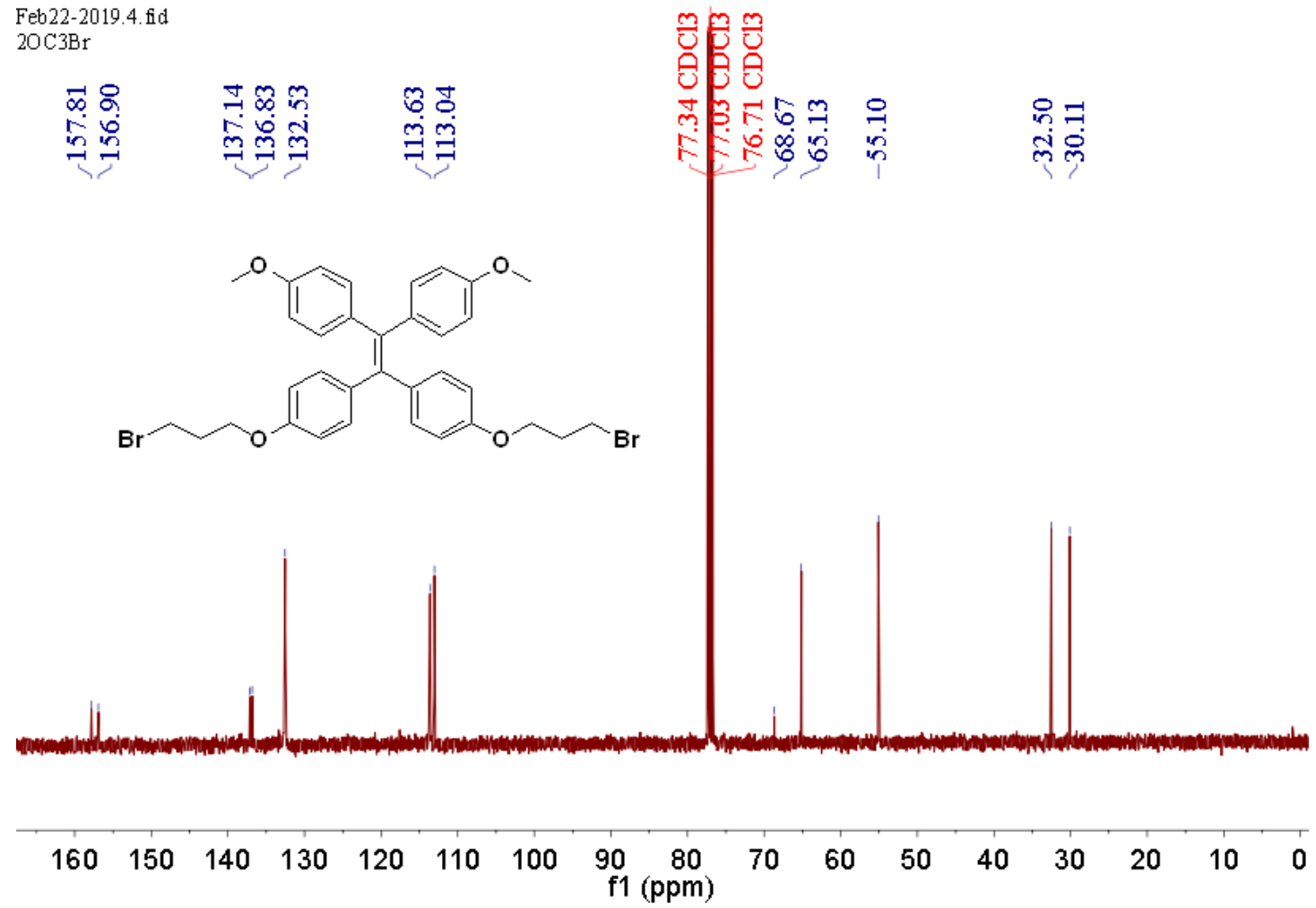

Figure S5 ${ }^{13} \mathrm{C}$ NMR spectrum of TPE- $2 \mathrm{OC}_{3} \mathrm{Br}$ in Chloroform-d. 


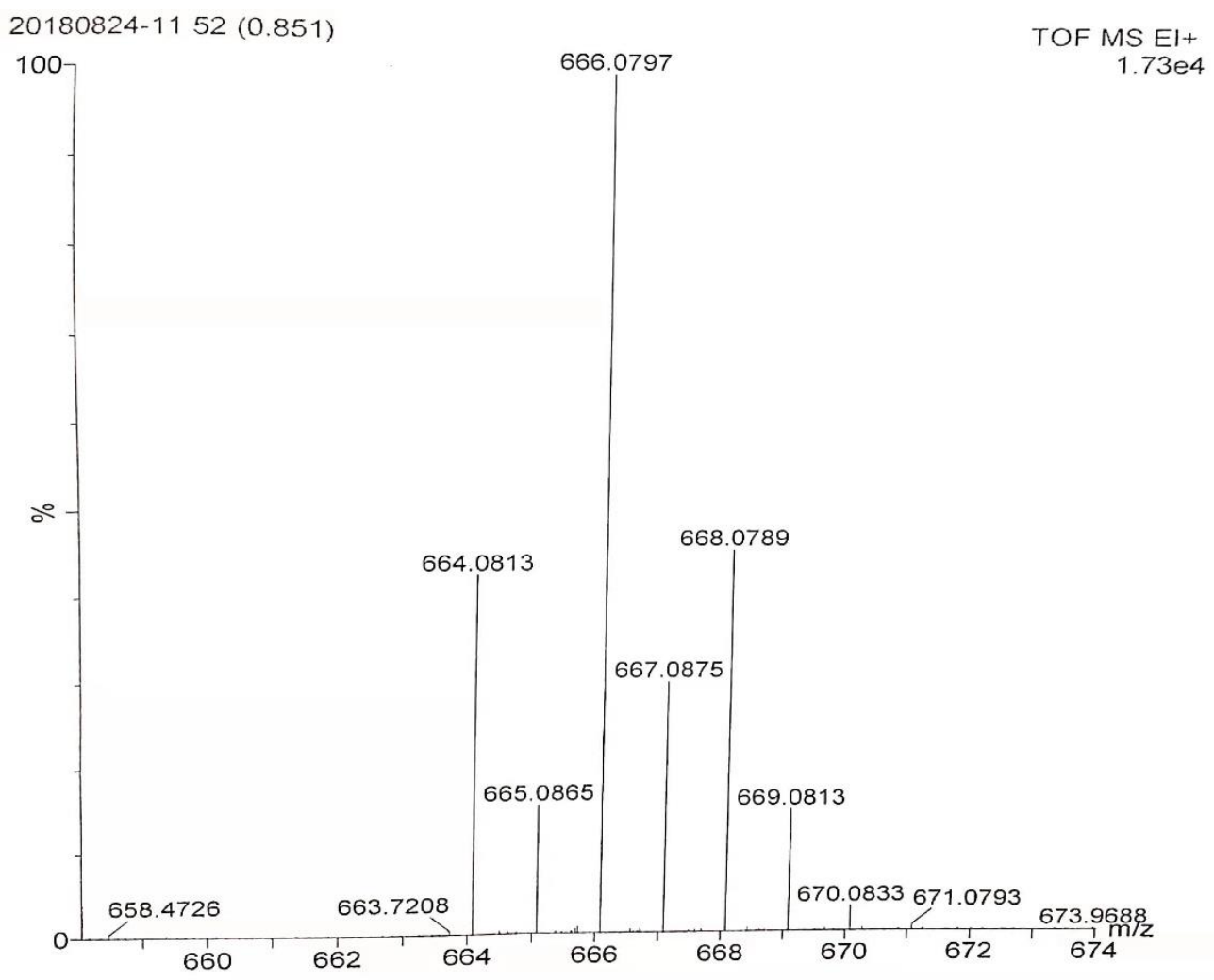

Figure S6 HRMS spectrum of TPE- $2 \mathrm{OC}_{3} \mathrm{Br}$.

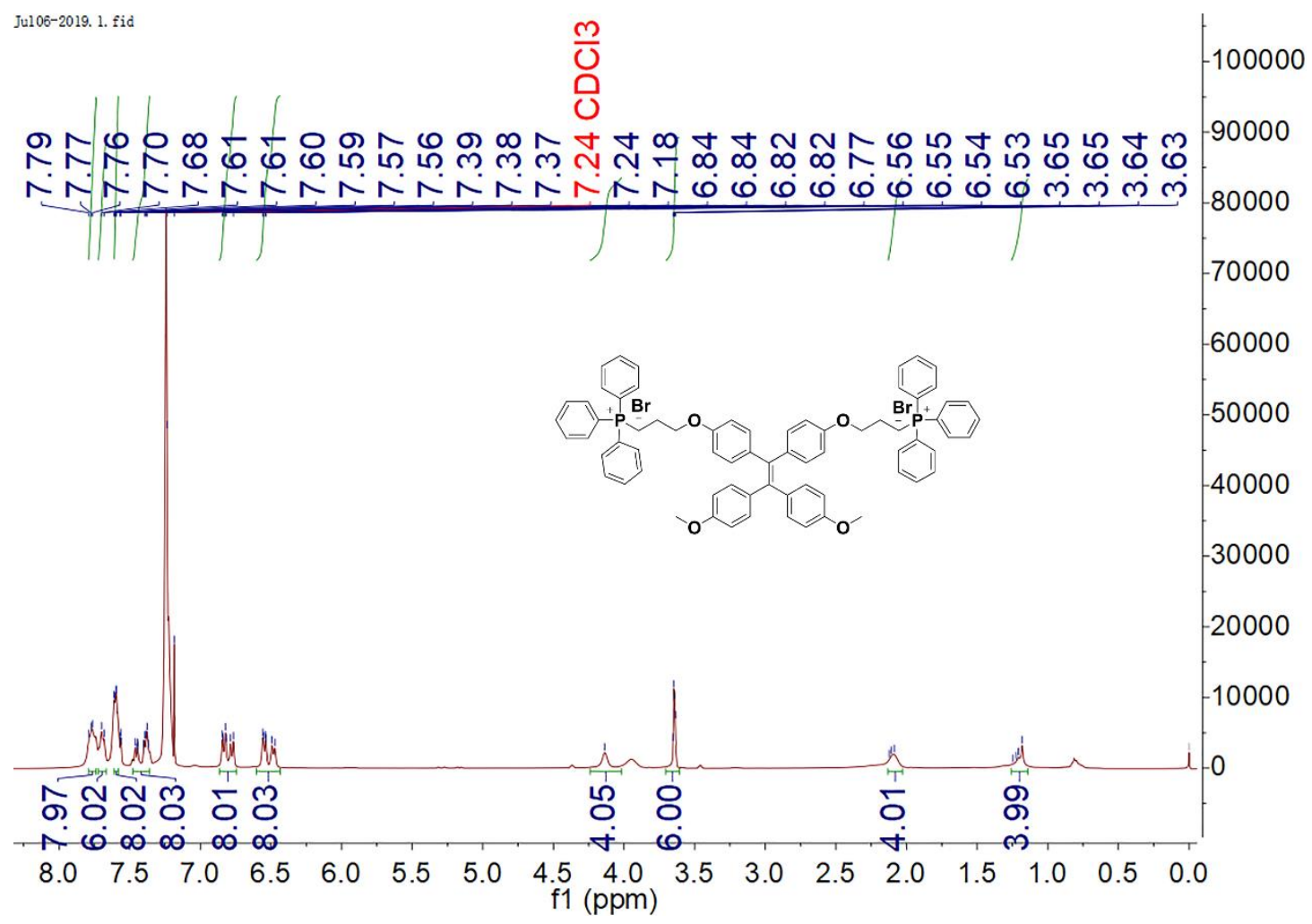

Figure S7 ${ }^{1} \mathrm{H}$ NMR spectrum of PT1 in Chloroform-d. 


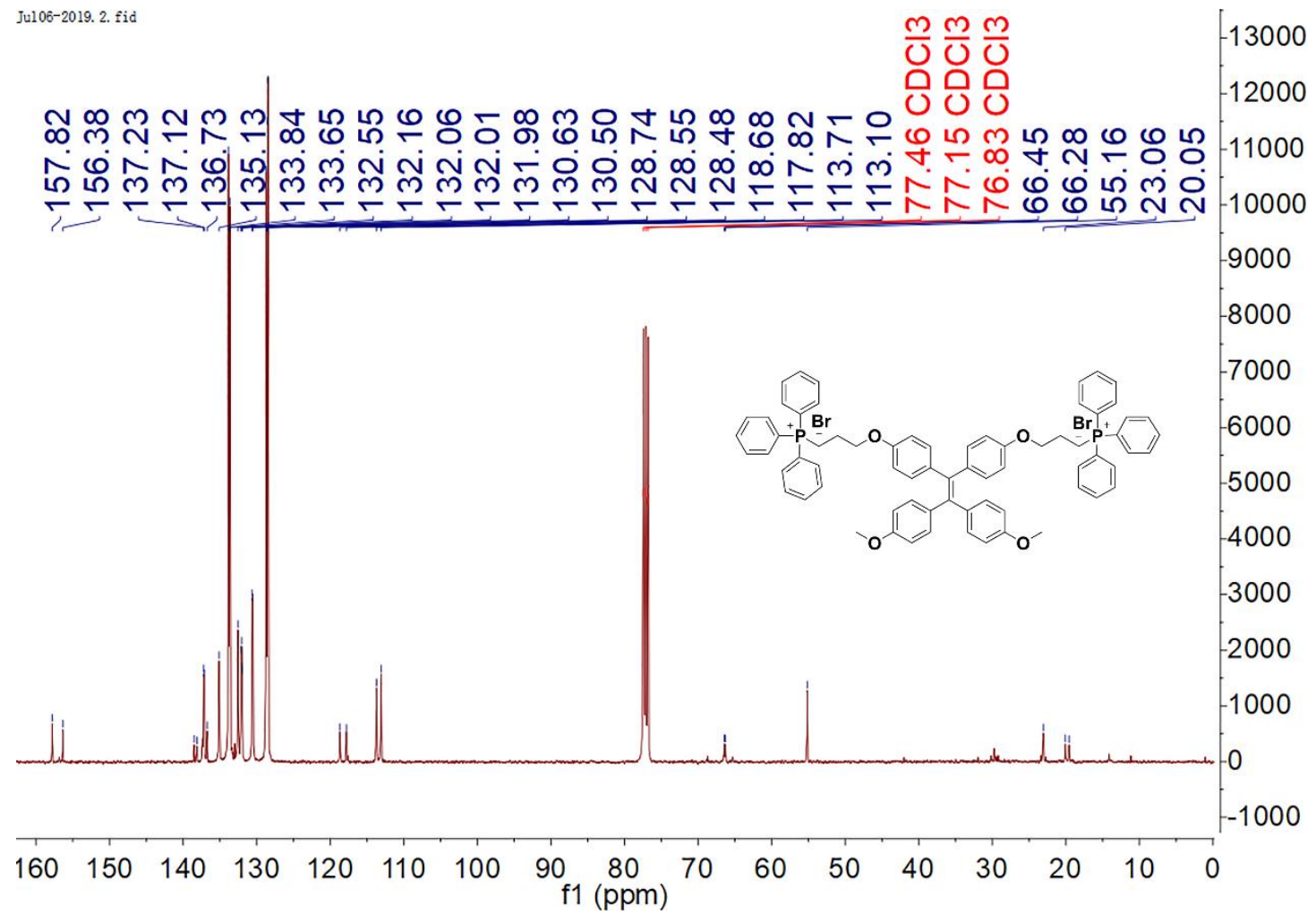

Figure S8 ${ }^{13} \mathrm{C}$ spectrum of PT1 in Chloroform-d.

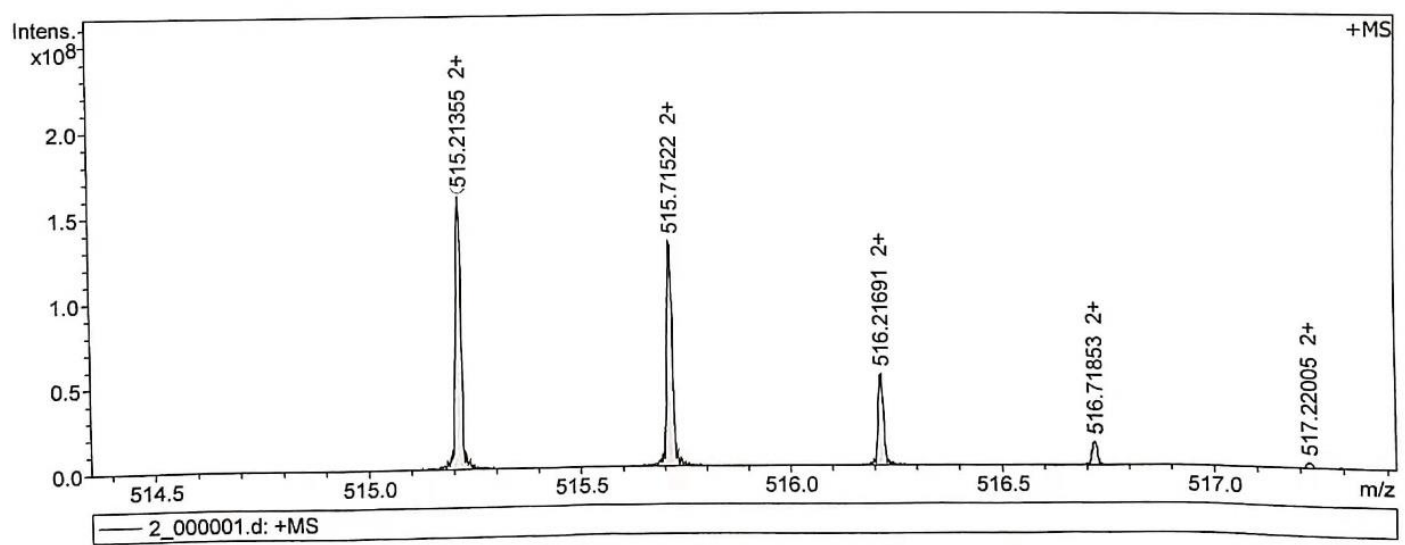

Figure S9 HRMS spectrum of PT1. 


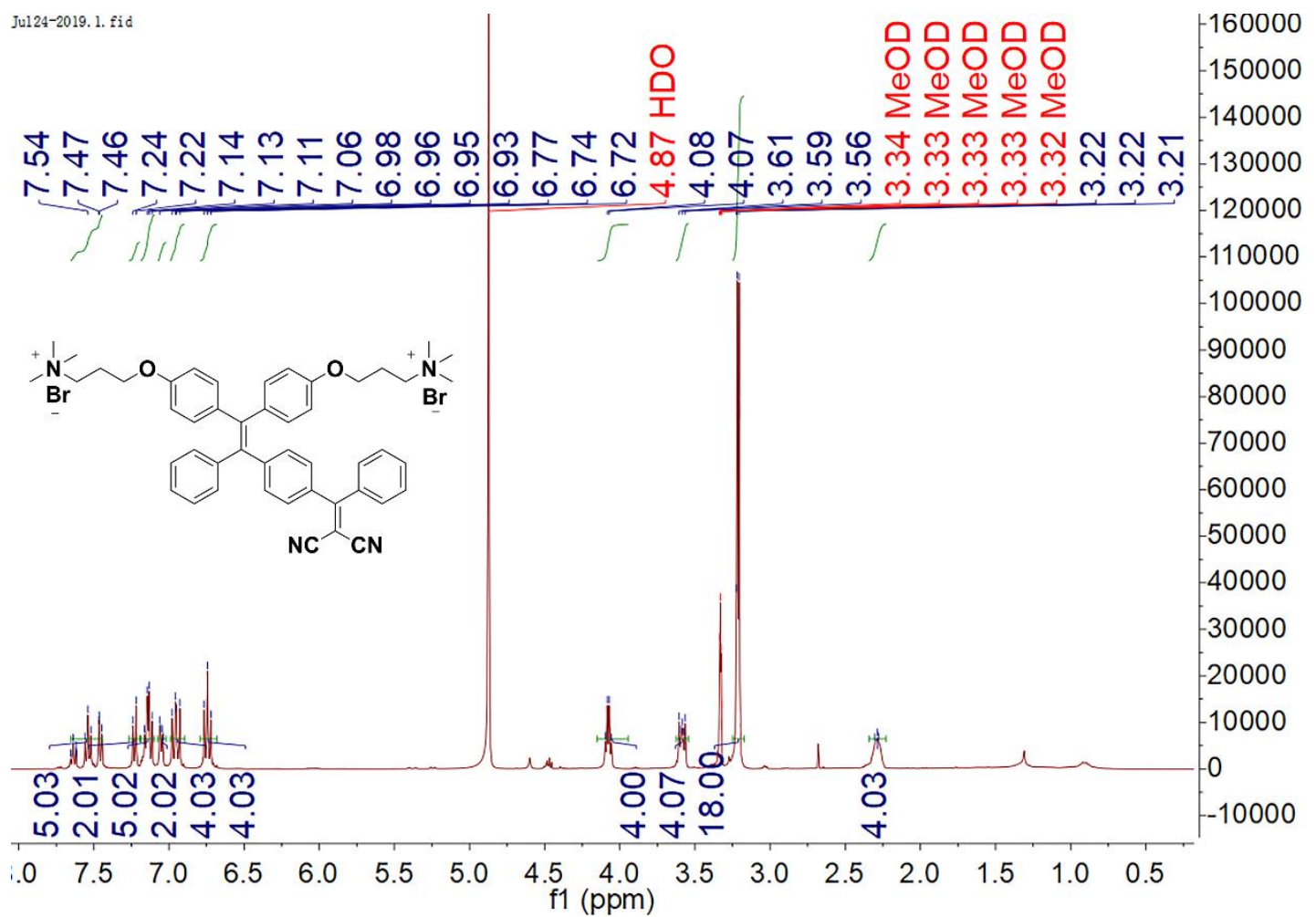

Figure S10 ${ }^{1} \mathrm{H}$ NMR spectrum of PT2 in methanol-d4.

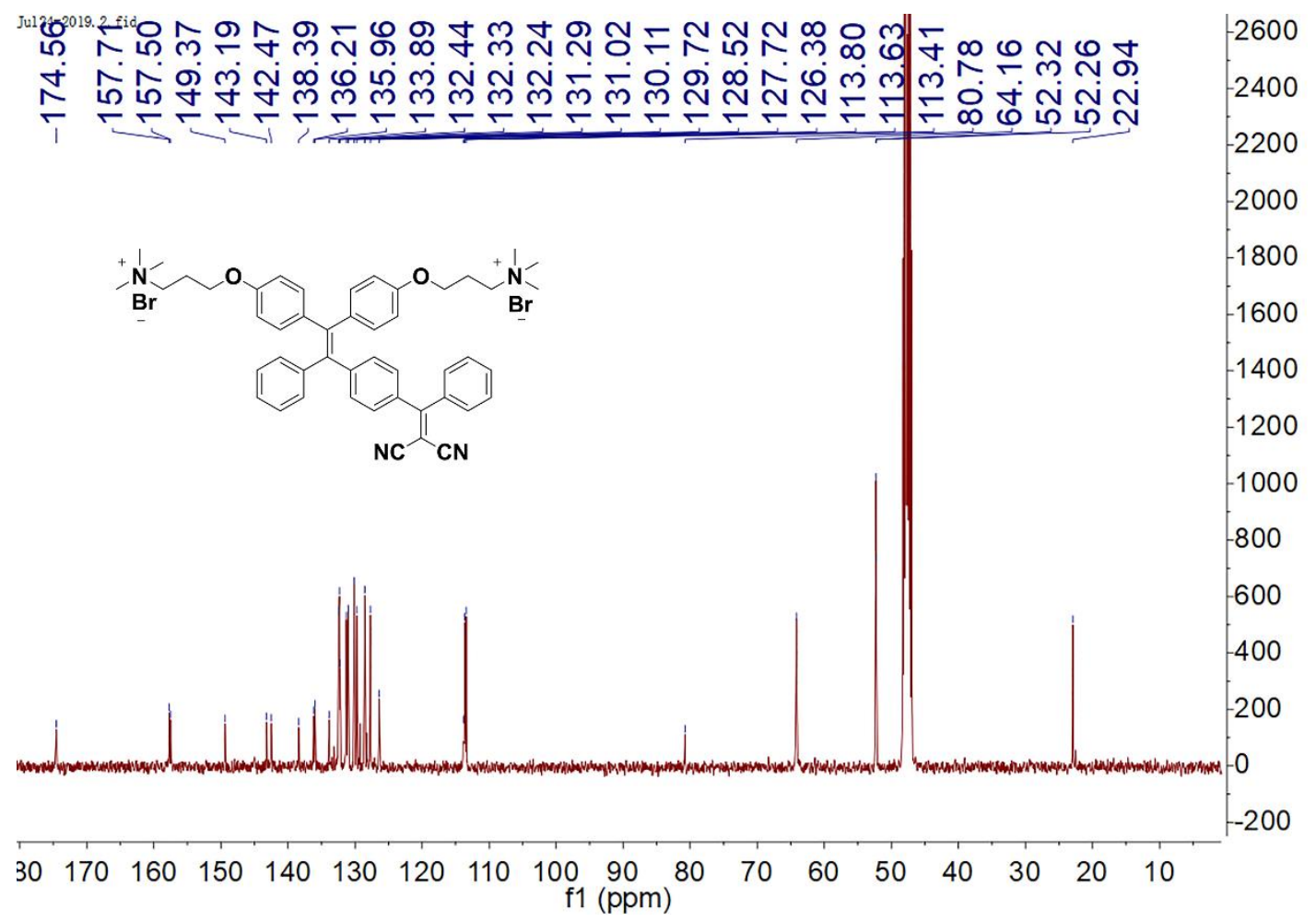

Figure S11 ${ }^{13} \mathrm{C}$ NMR spectrum of PT2 in methanol-d 4. 


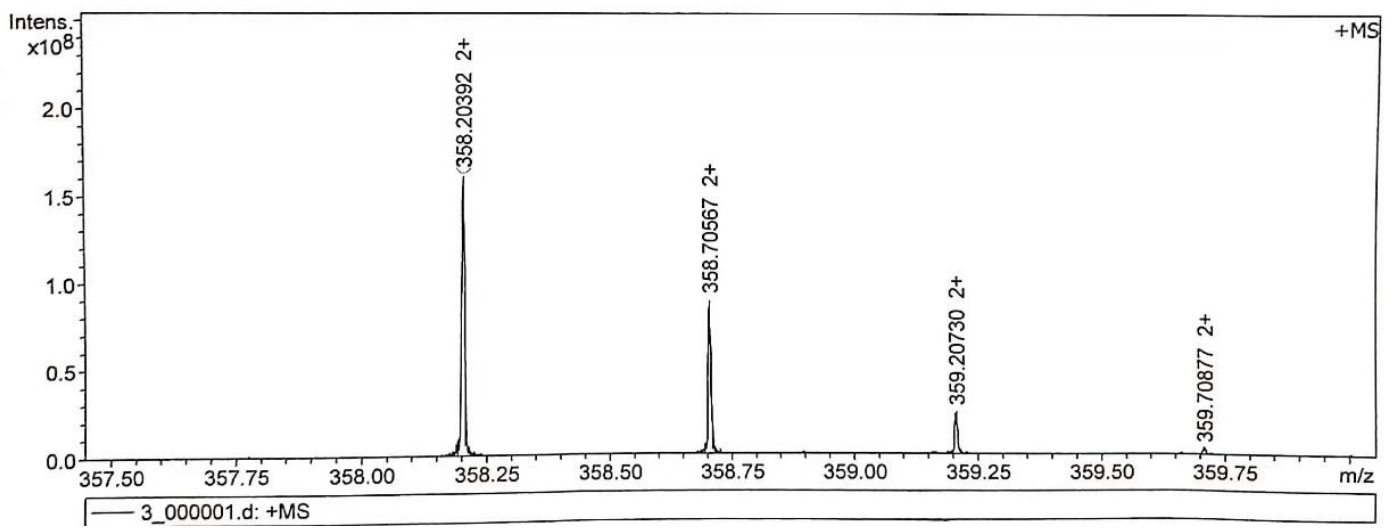

Figure S12 HRMS spectrum of PT2.

Nov01-2019.1.fid
2py

O

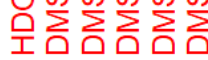

ఎ

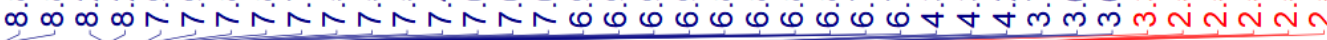

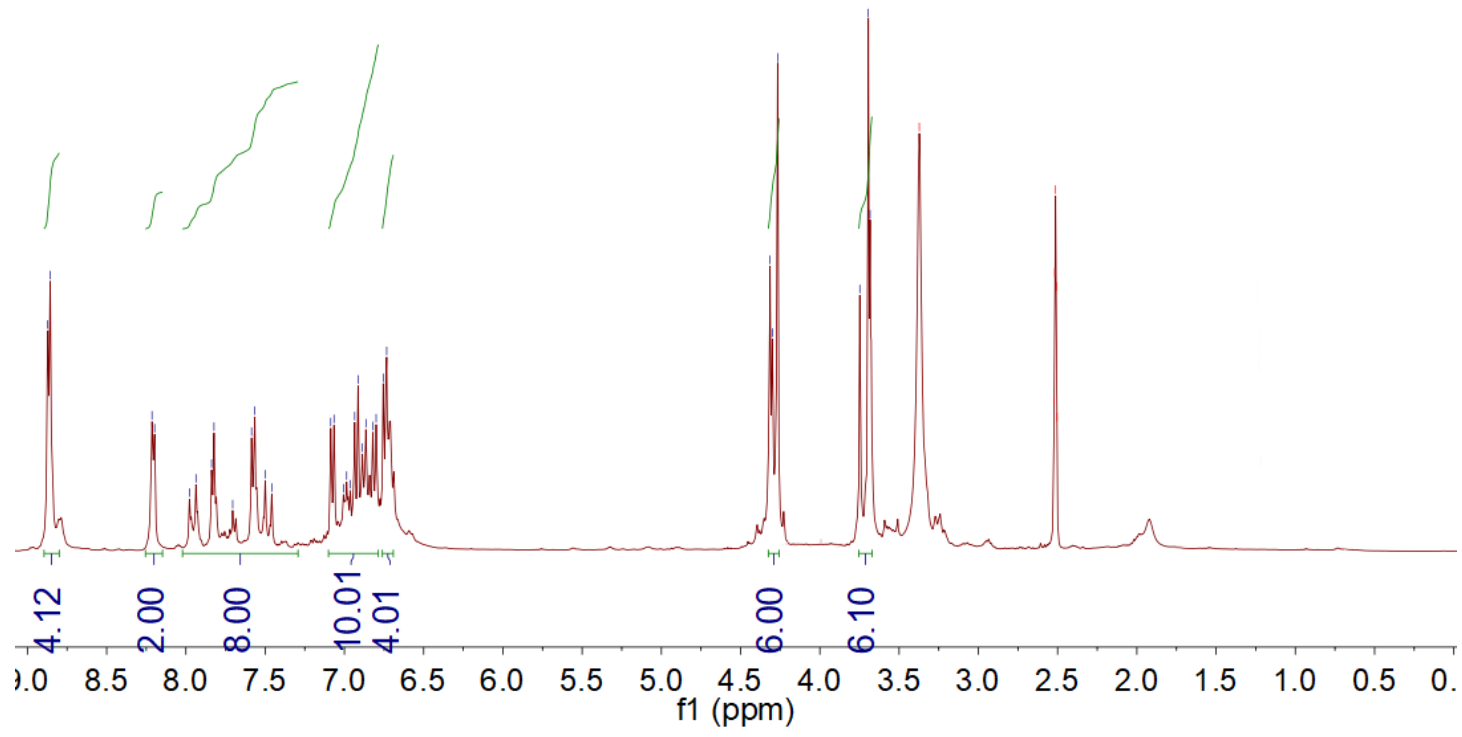

Figure S13 ${ }^{1}$ H NMR spectrum of PT3 in DMSO-d6. 


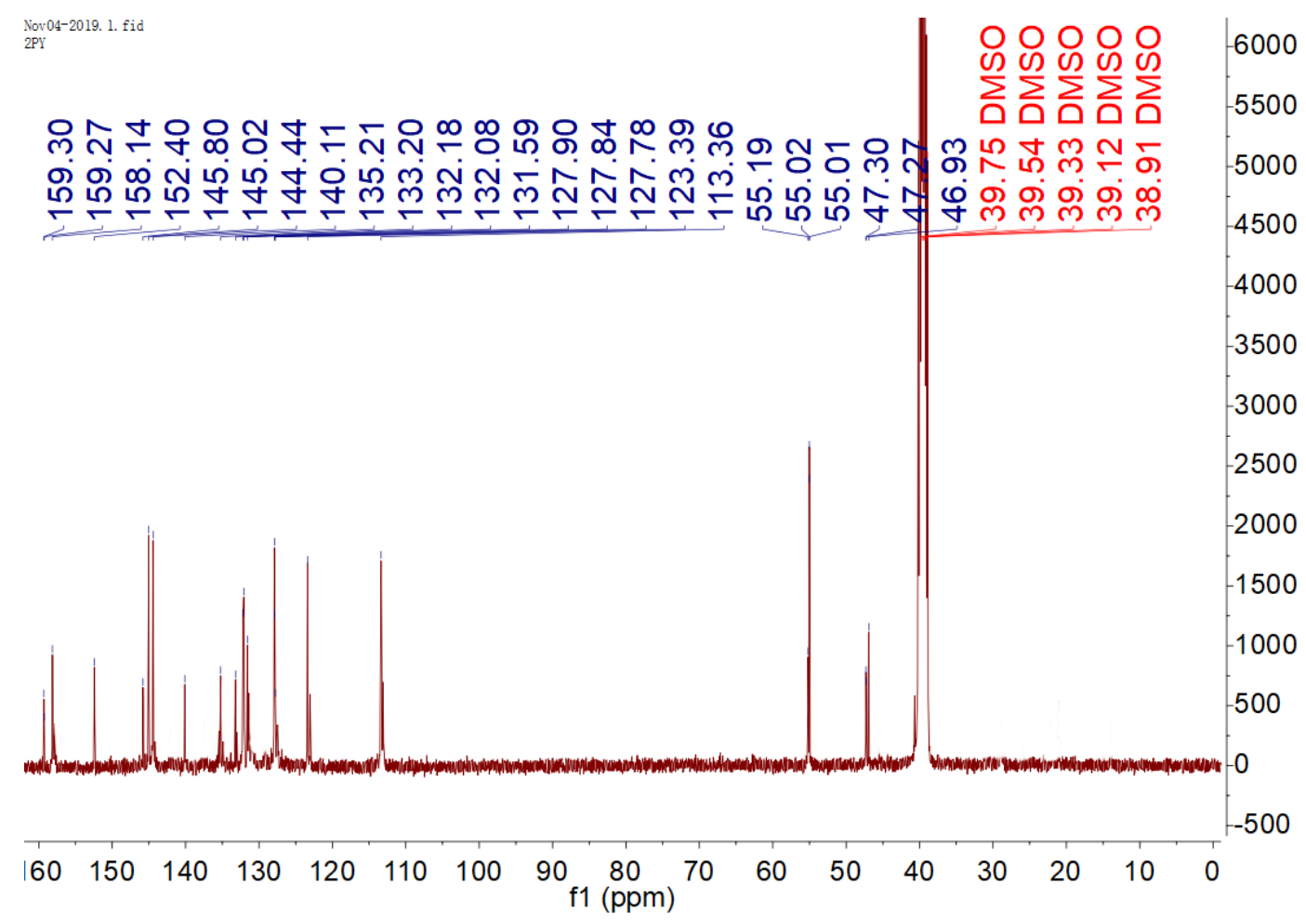

Figure S14 ${ }^{13} \mathrm{C}$ NMR spectrum of PT3 in DMSO-d 6 .

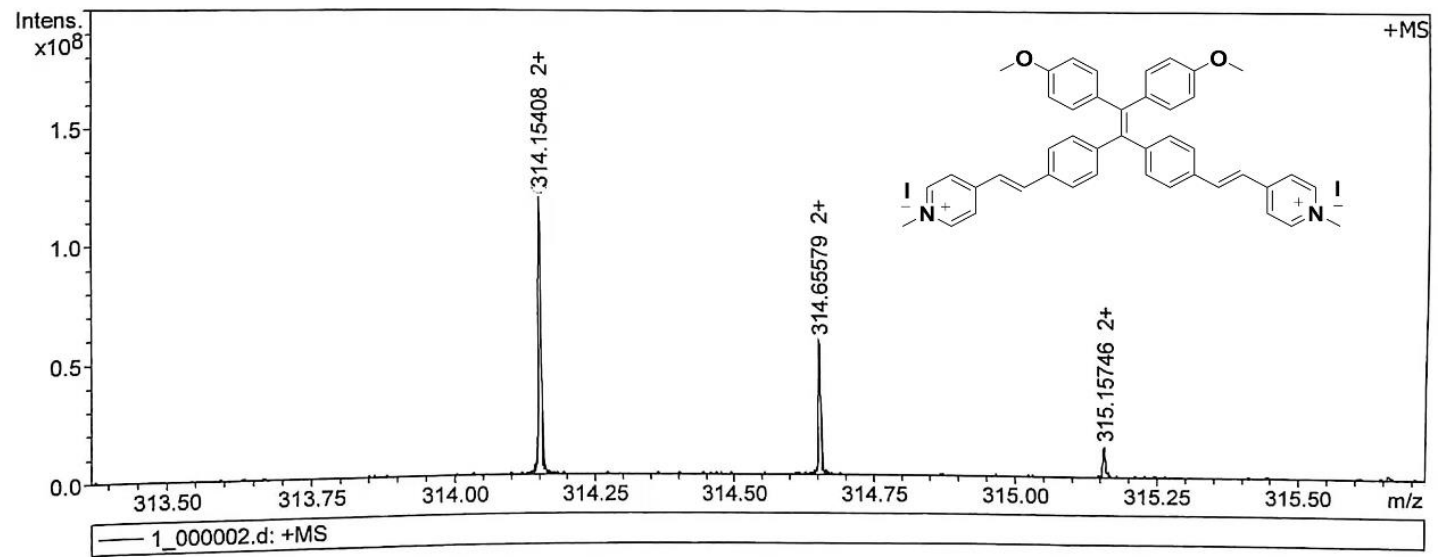

Figure S15 HRMS spectrum of PT3. 


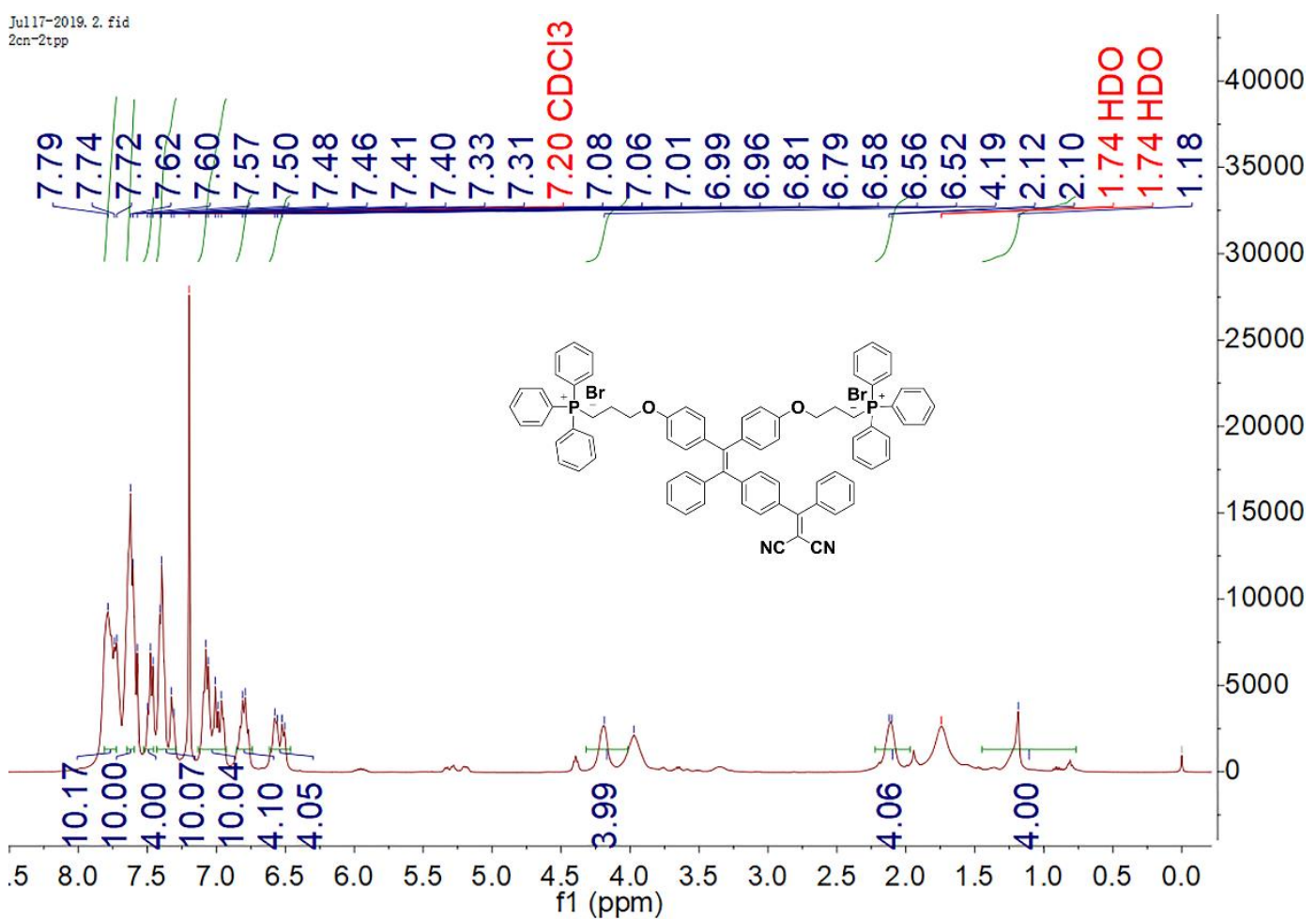

Figure S16 ${ }^{1} \mathrm{H}$ NMR spectrum of PT4 in Chloroform-d.

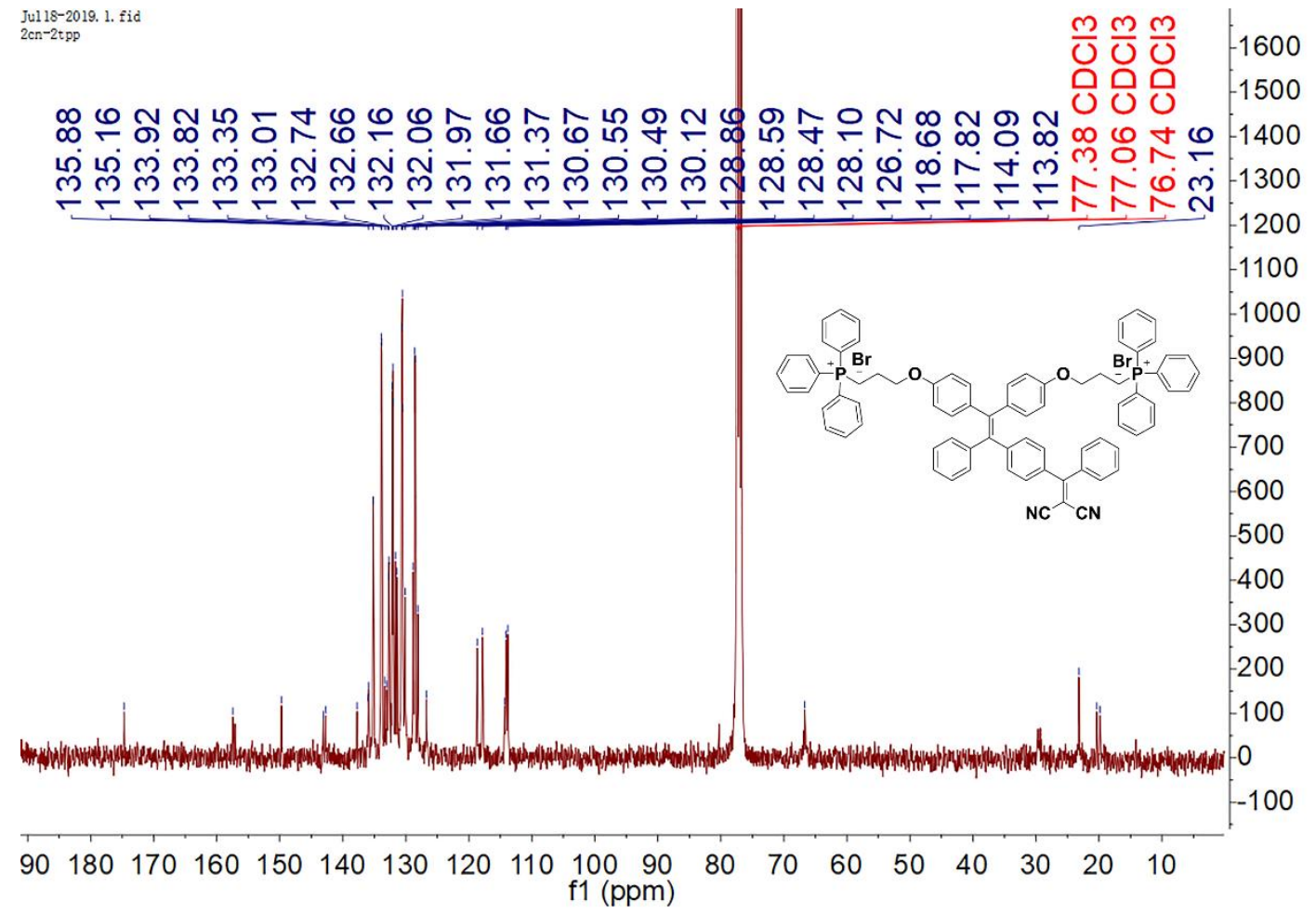

Figure S17 ${ }^{13} \mathrm{C}$ NMR spectrum of PT4 in Chloroform-d. 


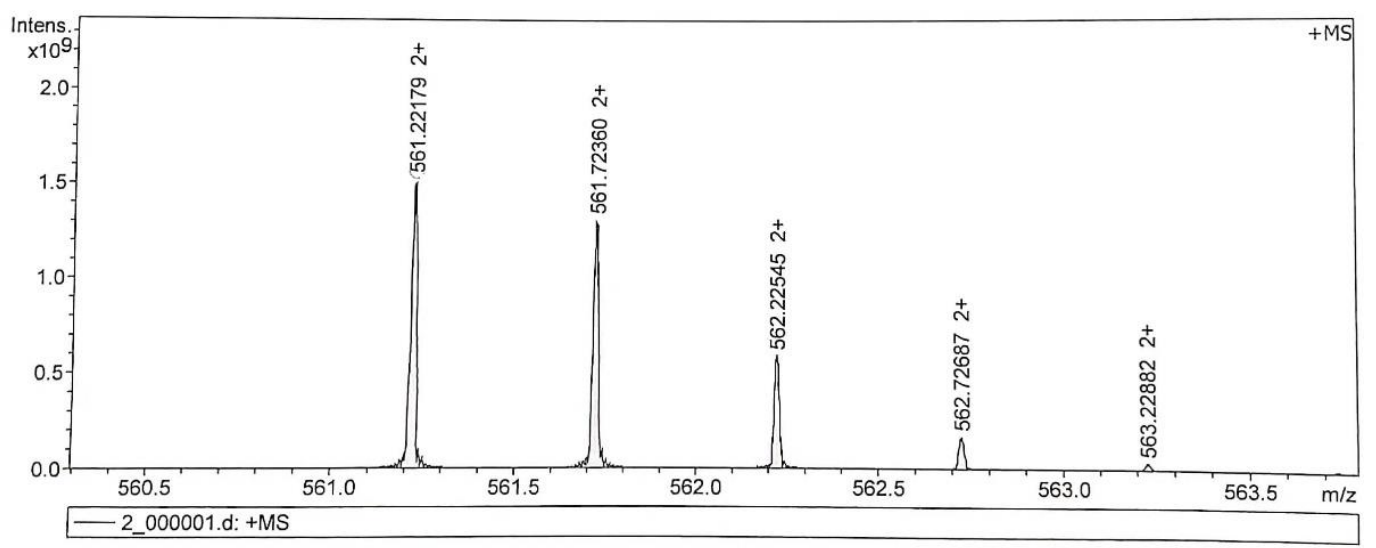

Figure S18 HRMS spectrum of PT4.

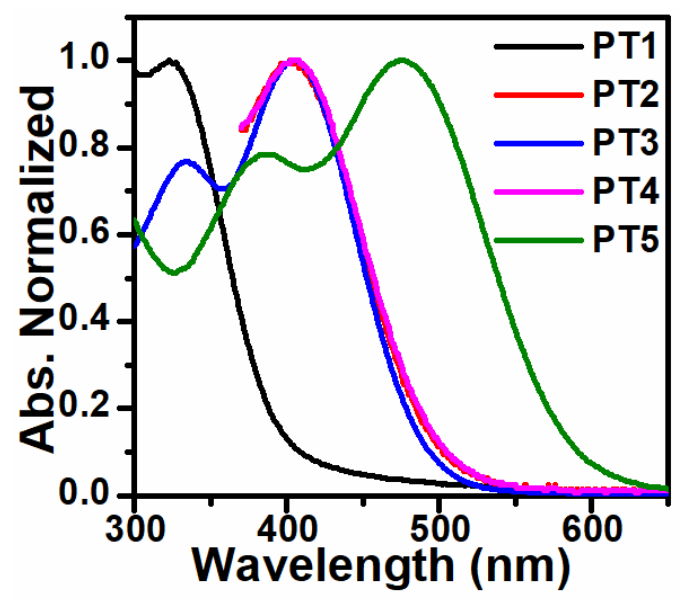

Figure S19 The absorption spectra of PTx in 65\% glycerol solution.
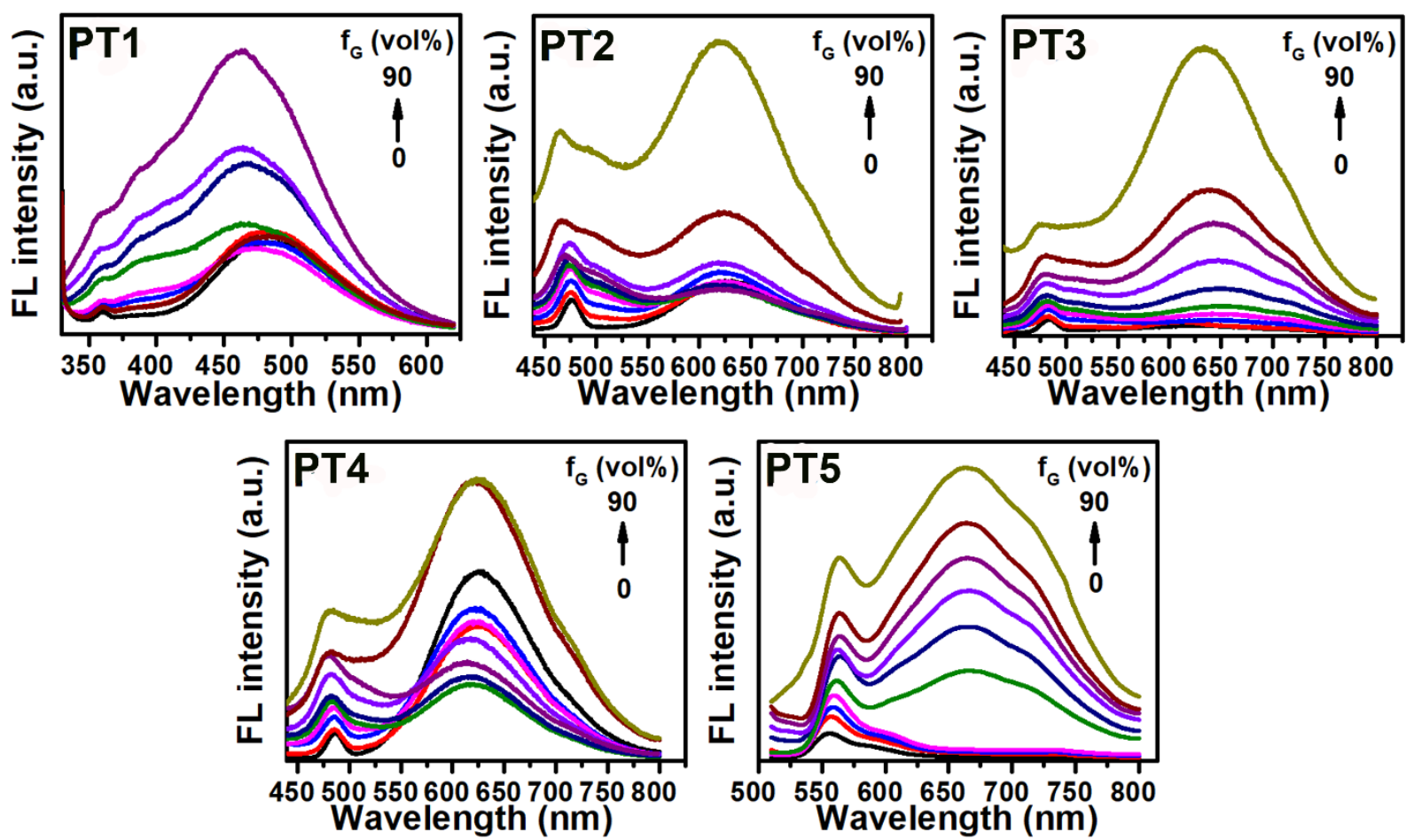

Figure S20 Fluorescence intensity spectra of PTx $(10 \mu \mathrm{M})$ in glycerol aqueous solution with different glycerol fraction $\left(f_{G}\right)$. 

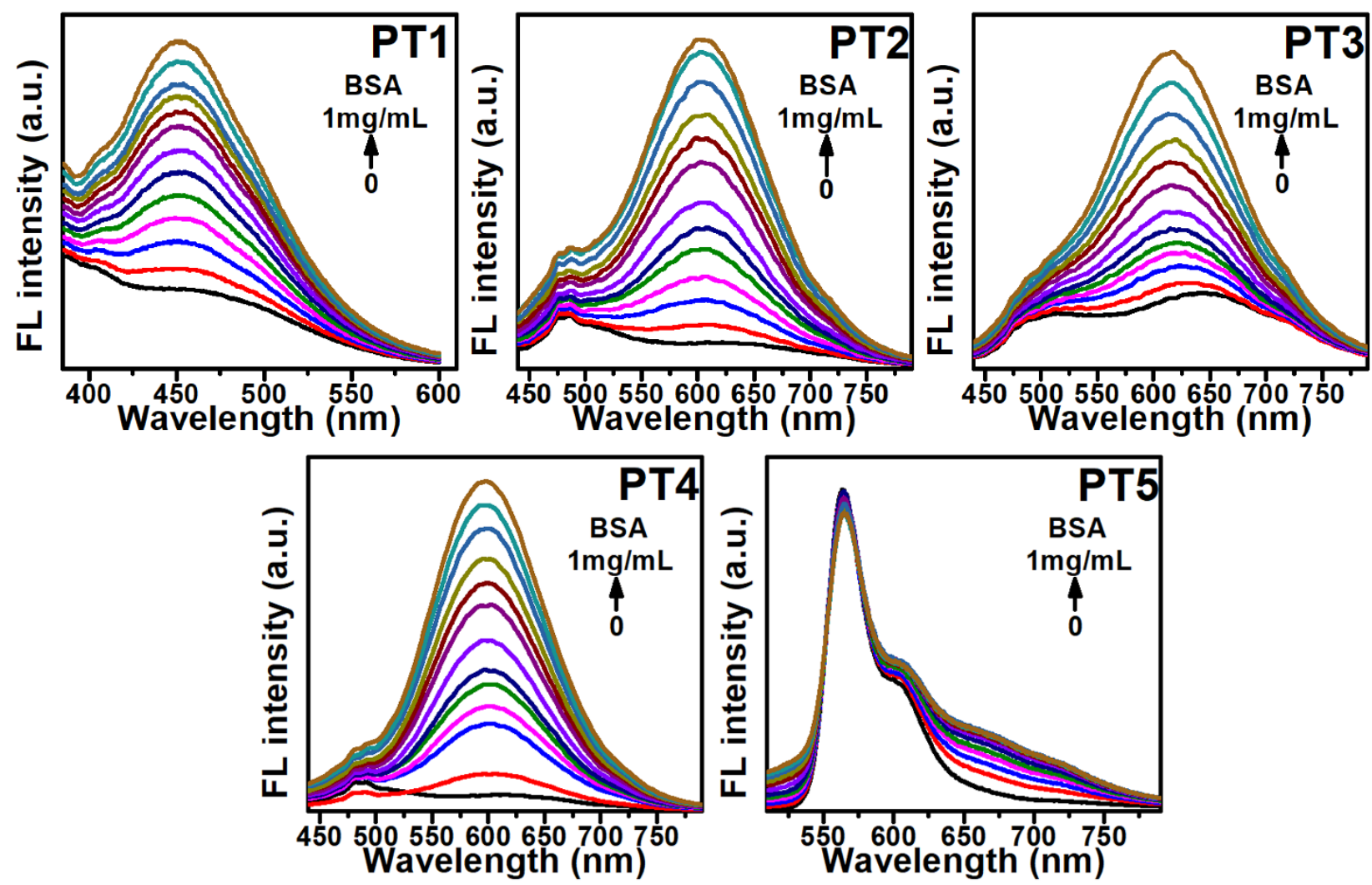

Figure S21 Fluorescence intensity spectra of PTx $(10 \mu \mathrm{M})$ with various concentration of BSA.
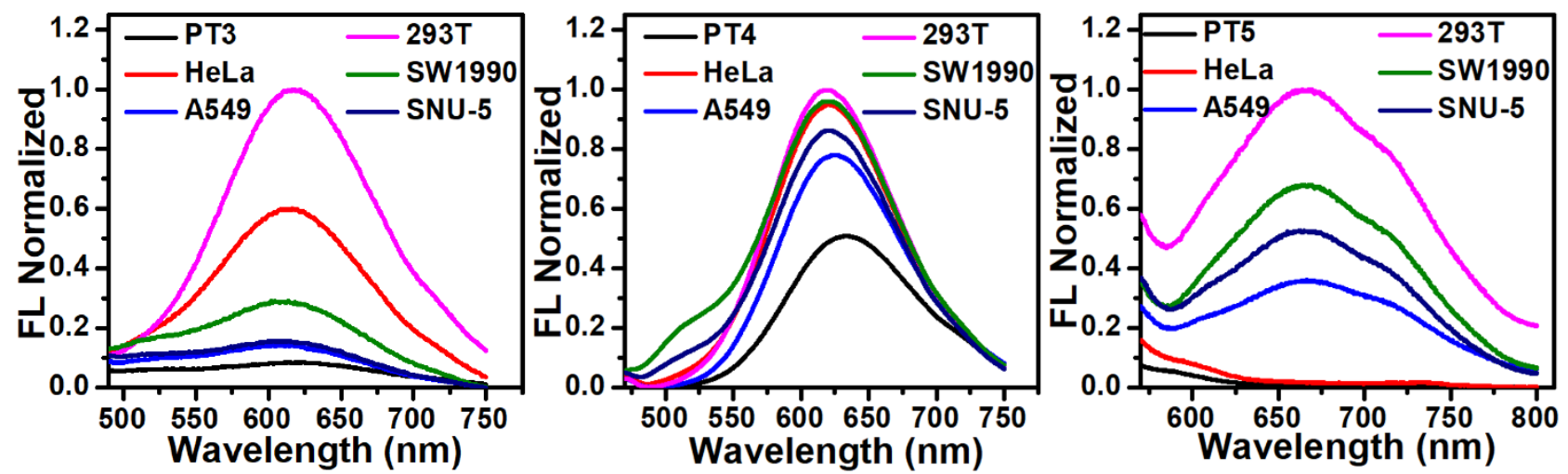

Figure S22 The normalized fluorescence intensity of $10 \mu \mathrm{M}$ PTx $(x=3,4,5,6)$ in PBS and different cells suspensions with 10000 cells. 

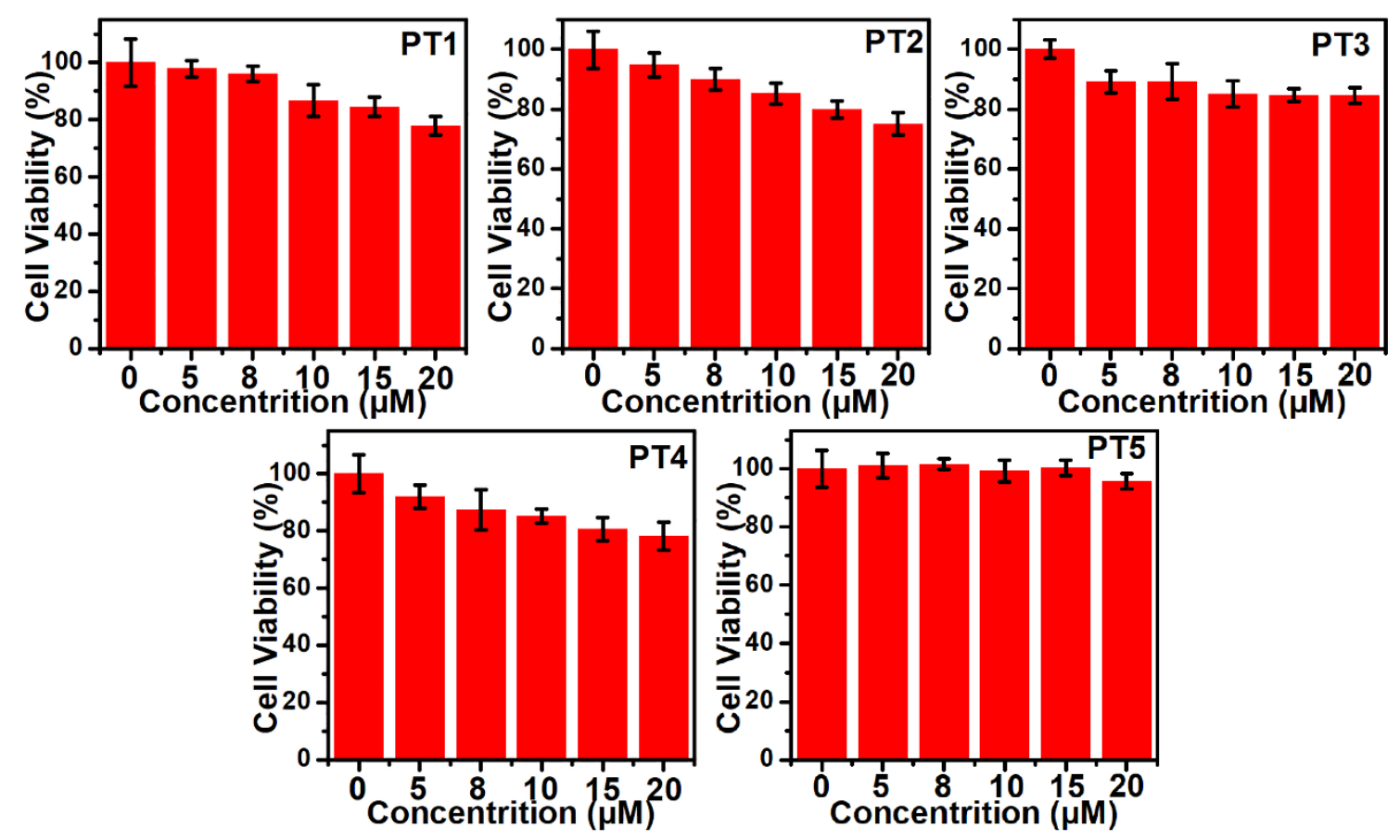

Figure S23 Cytotoxicity of PTx evaluated on HeLa cells by MTT assay.

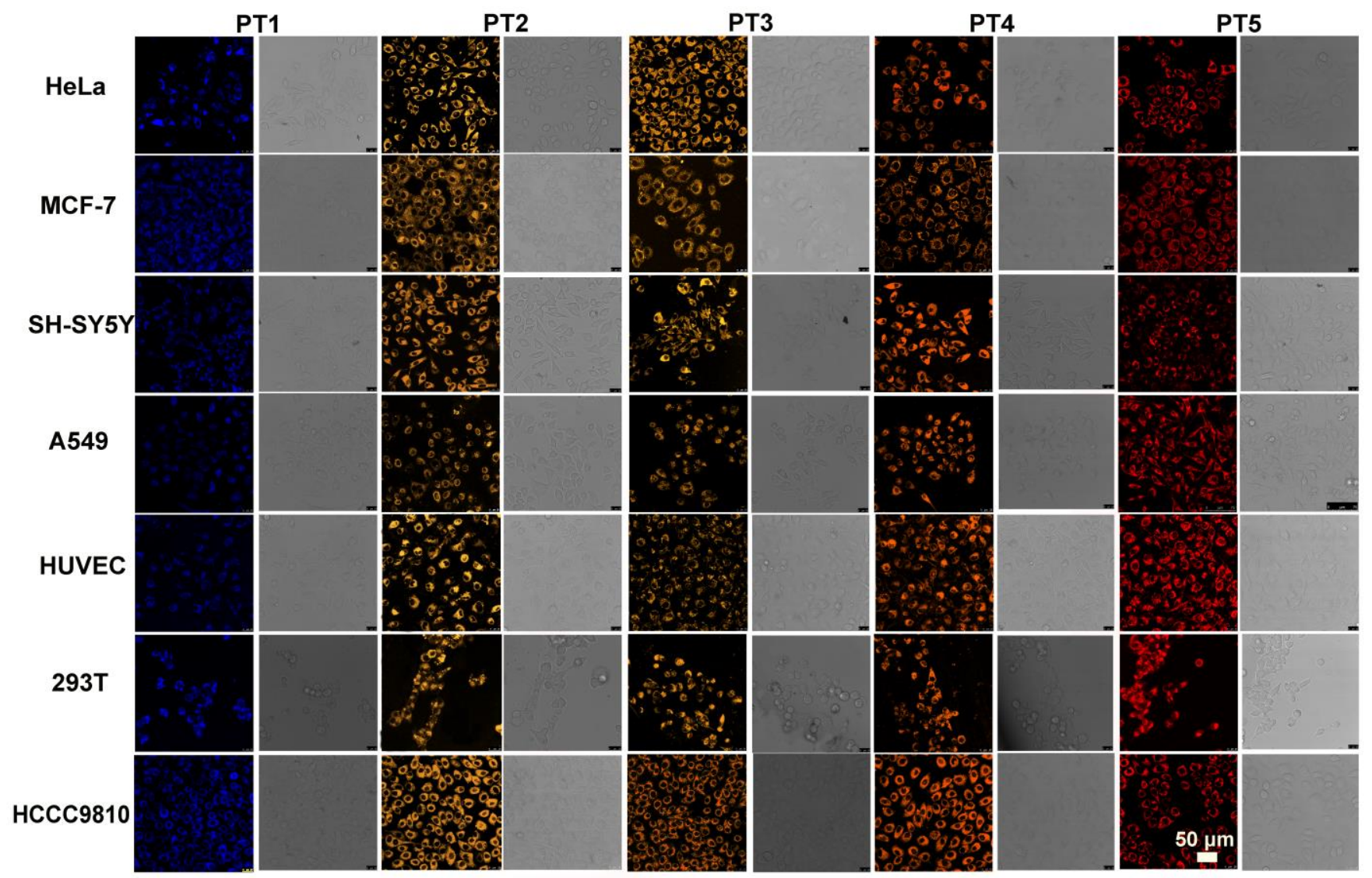

Figure S24 Confocal fluorescence images of seven kinds of different cells stain with $10 \mu \mathrm{M}$ PTx. The different color representation (blue, orange, red) is consistent with the maximum value of fluorescence. 


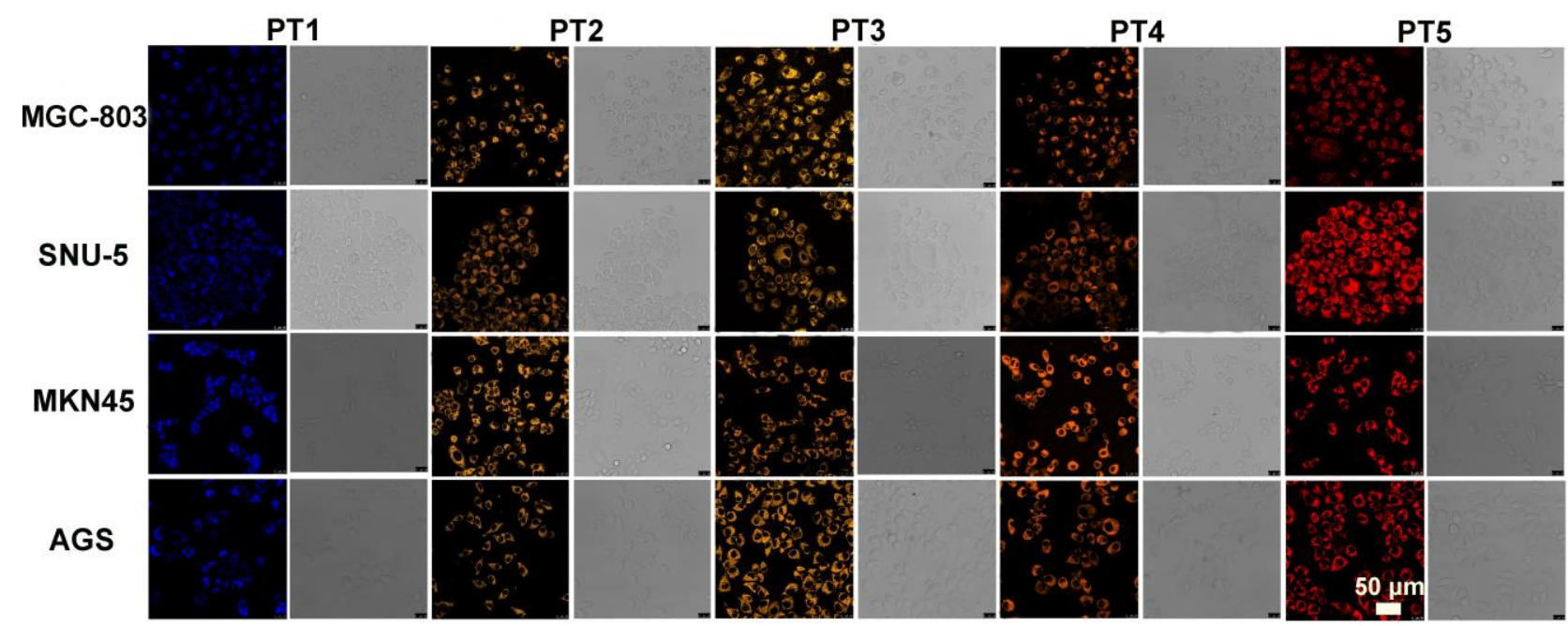

Figure S25 Confocal fluorescent images of four kinds of gastric cells stain with $10 \mu \mathrm{M}$ PTx. The different color representation (blue, orange, red) is consistent with the maximum value of fluorescence. The scale bar is $50 \mu \mathrm{m}$.
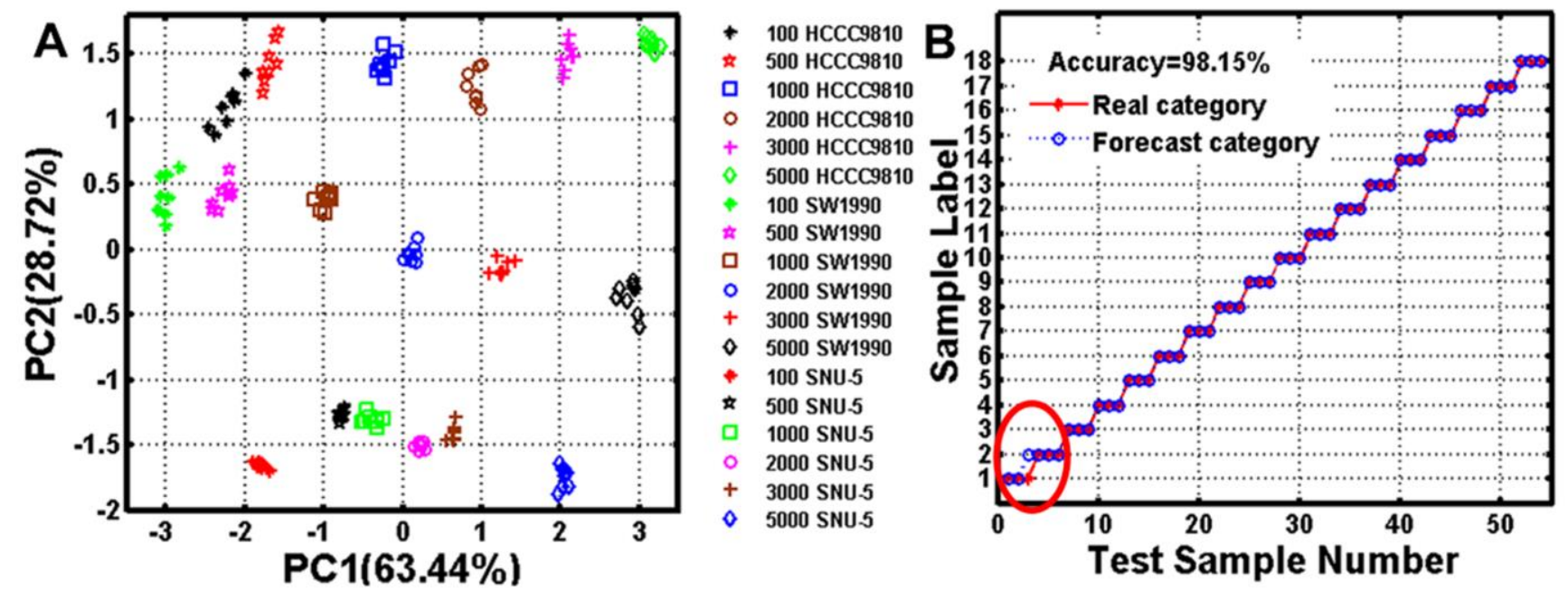

Figure S26 The minimum detectable cell concentration of the PTx-Sa. (A) Canonical score plot determined by PCA for the different fluorescence response of PTx with various cell concentrations. (B) Unknown cell type prediction results by SVM. 

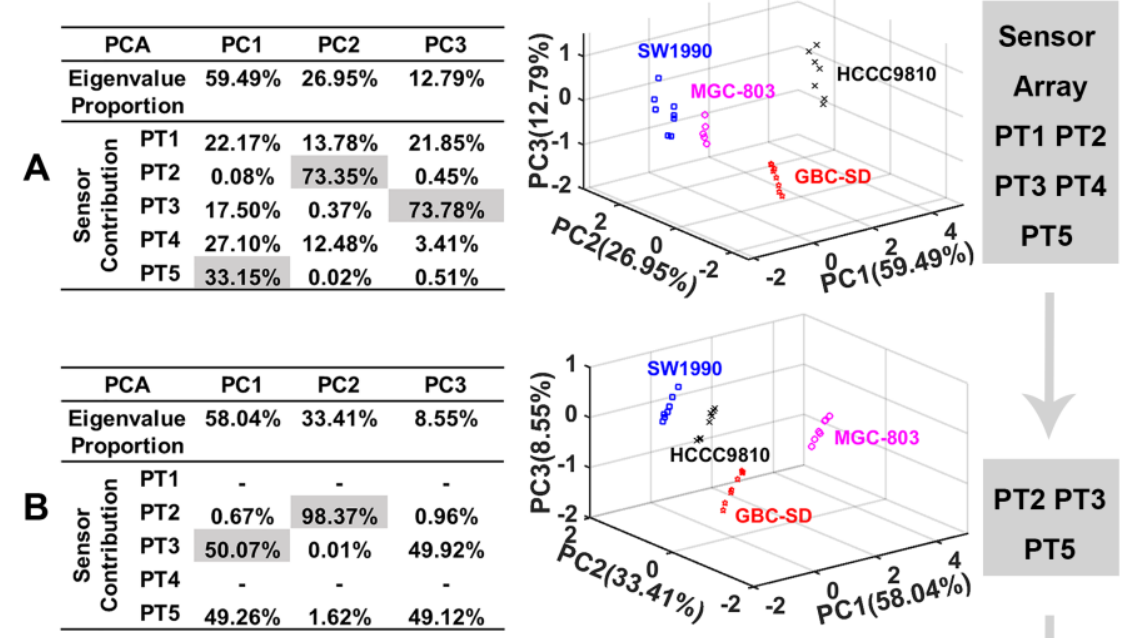

PT5
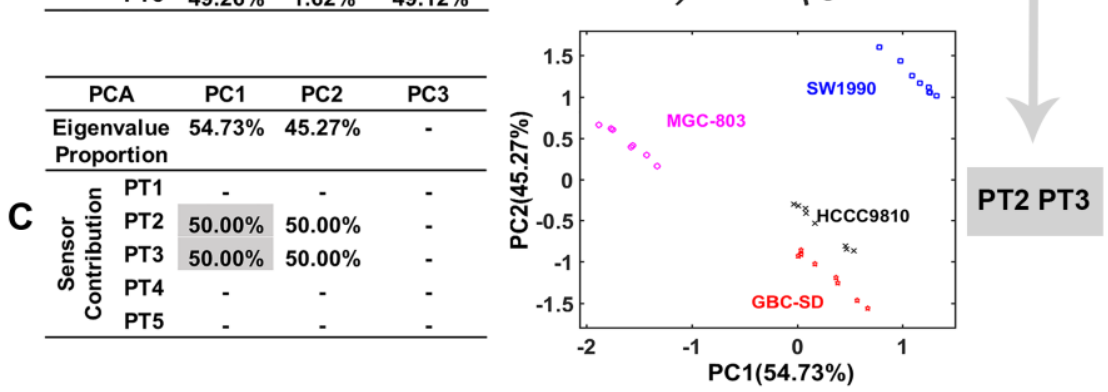

Figure S27 Schematic diagram of the contribution of the probes to the main components (PC1, PC2, PC3) in the sensor array in digestive tract cancer cells: (A) PCA analysis of PTx-Sa shows that the main contributors to the different cell lines identification are PT2, PT3 and PT5. (B) The data set of PT2, PT3 and PT5 are analyzed by PCA again, indicating that the main contributors are PT2 and PT3. (C) The data set of PT2 and PT3 are finally used for PCA analysis.

Table S1 Properties of PTx.

\begin{tabular}{lccccc}
\hline & $\lambda_{\text {ex }}(\mathrm{nm})^{[\mathrm{a}]}$ & $\lambda_{\mathrm{em}}(\mathrm{nm})^{[\mathrm{b}]}$ & $\alpha_{\text {AIE }}{ }^{[\mathrm{c}]}$ & $\Phi_{\mathrm{f}}(\%)^{[\mathrm{d}]}$ & CLogP [e] \\
\hline PT1 & 310 & 475 & 3.24 & 31.63 & 10.63 \\
PT2 & 415 & 625 & 6.45 & 24.93 & 2.16 \\
PT3 & 417 & 625 & 27.97 & 17.54 & 1.16 \\
PT4 & 420 & 640 & 3.74 & 51.46 & 10.85 \\
PT5 & 488 & 690 & 84.37 & 15.38 & 3.45 \\
\hline
\end{tabular}

[a] Maximum excitation wavelength in $65 \%$ glycerol aqueous solution; [b] The maximum emission wavelength in the aggregate state; [c] $\alpha_{\mathrm{AIE}}=\operatorname{Imax} / \mathrm{I}_{0}, \operatorname{Imax}$ is the maximum emission intensity in the aggregate state, $\mathrm{I}_{0}$ is the maximum emission intensity in solution; [d] Absolute fluorescence quantum yield of PTx in solid state. [e] CLogP is n-octanol/water partition coefficient, whose value is estimated in http://146.107.217.178/lab/alogps/start.html. 
Table S2 SVM results for identification of unknown samples within the reference set for seven different cells using PTx-Sa.

\begin{tabular}{cccc}
\hline No. & True ID & Identified as & $\begin{array}{c}\text { SVM Correct } \\
\text { Identification }\end{array}$ \\
\hline 1 & Cervical & Cervical & Yes \\
2 & Cervical & Cervical & Yes \\
3 & Cervical & Cervical & Yes \\
4 & Breast & Breast & Yes \\
5 & Breast & Breast & Yes \\
6 & Breast & Breast & Yes \\
7 & Neuroblastoma & Neuroblastoma & Yes \\
8 & Neuroblastoma & Neuroblastoma & Yes \\
9 & Neuroblastoma & Neuroblastoma & Yes \\
10 & Lung & Lung & Yes \\
11 & Lung & Lung & Yes \\
12 & Lung & Lung & Yes \\
13 & Umbilical Vein Endothelial & Umbilical Vein Endothelial & Yes \\
14 & Umbilical Vein Endothelial & Umbilical Vein Endothelial & Yes \\
15 & Umbilical Vein Endothelial & Umbilical Vein Endothelial & Yes \\
16 & Renal Epithelial & Renal Epithelial & Yes \\
17 & Renal Epithelial & Renal Epithelial & Yes \\
18 & Renal Epithelial & Renal Epithelial & Yes \\
19 & Cholangiocarcinoma & Cholangiocarcinoma & Yes \\
20 & Cholangiocarcinoma & Cholangiocarcinoma & Yes \\
21 & Cholangiocarcinoma & Cholangiocarcinoma & Yes \\
\hline & & &
\end{tabular}


Table S3 SVM results for identification of unknown samples within the reference set for four different digestive tract cell lines using PTx-Sa.

\begin{tabular}{cccc}
\hline No. & True ID & Identified as & $\begin{array}{c}\text { SVM Correct } \\
\text { Identification }\end{array}$ \\
\hline 1 & HCCC9810 & HCCC9810 & Yes \\
2 & HCCC9810 & HCCC9810 & Yes \\
3 & HCCC9810 & HCCC9810 & Yes \\
4 & HCCC9810 & HCCC9810 & Yes \\
5 & HCCC9810 & HCCC9810 & Yes \\
6 & GBC-SD & GBC-SD & Yes \\
7 & GBC-SD & GBC-SD & Yes \\
8 & GBC-SD & GBC-SD & Yes \\
9 & GBC-SD & GBC-SD & Yes \\
10 & GBC-SD & GBC-SD & Yes \\
11 & SW1990 & SW1990 & Yes \\
12 & SW1990 & SW1990 & Yes \\
13 & SW1990 & SW1990 & Yes \\
14 & SW1990 & SW1990 & Yes \\
15 & SW1990 & SW1990 & Yes \\
16 & MGC-803 & MGC-803 & Yes \\
17 & MGC-803 & MGC-803 & Yes \\
18 & MGC-803 & MGC-803 & Yes \\
19 & MGC-803 & MGC-803 & Yes \\
20 & MGC-803 & MGC-803 & Yes \\
\hline
\end{tabular}

Table S4 SVM results for identification of unknown samples within the reference set for four different gastric cell lines using PTx-Sa.

\begin{tabular}{cccc}
\hline No. & True ID & Identified as & $\begin{array}{c}\text { SVM Correct } \\
\text { Identification }\end{array}$ \\
\hline 1 & MGC-803 & MGC-803 & Yes \\
2 & MGC-803 & MGC-803 & Yes \\
3 & MGC-803 & MGC-803 & Yes \\
4 & MGC-803 & MGC-803 & Yes \\
5 & MGC-803 & MGC-803 & Yes \\
6 & SNU-5 & SNU-5 & Yes \\
7 & SNU-5 & SNU-5 & Yes \\
8 & SNU-5 & SNU-5 & Yes \\
9 & SNU-5 & SNU-5 & Yes \\
10 & SNU-5 & SNU-5 & Yes \\
11 & MKN45 & MKN45 & Yes \\
12 & MKN45 & MKN45 & Yes \\
13 & MKN45 & MKN45 & Yes \\
14 & MKN45 & MKN45 & Yes \\
15 & MKN45 & MKN45 & Yes \\
16 & AGS & AGS & Yes \\
17 & AGS & AGS & Yes \\
18 & AGS & AGS & Yes \\
19 & AGS & AGS & Yes \\
20 & AGS & AGS & Yes \\
\hline
\end{tabular}


Table S5 SVM results for identification of unknown samples within the reference set for mixed gastric cell lines using PTx-Sa. a is MGC-803, b is SNU-5, c is MKN45, d is AGS.

\begin{tabular}{|c|c|c|c|}
\hline No. & True ID & Identified as & $\begin{array}{l}\text { SVM Correct } \\
\text { Identification }\end{array}$ \\
\hline 1 & $a+b$ & $a+b$ & Yes \\
\hline 2 & $a+b$ & $a+b$ & Yes \\
\hline 3 & $a+b$ & $a+b$ & Yes \\
\hline 4 & $a+c$ & $a+c$ & Yes \\
\hline 5 & $a+c$ & $a+c$ & Yes \\
\hline 6 & $a+c$ & $a+c$ & Yes \\
\hline 7 & $a+d$ & $a+d$ & Yes \\
\hline 8 & $a+d$ & $a+d$ & Yes \\
\hline 9 & $a+d$ & $a+d$ & Yes \\
\hline 10 & $b+c$ & $b+c$ & Yes \\
\hline 11 & $b+c$ & $b+c$ & Yes \\
\hline 12 & $b+c$ & $b+c$ & Yes \\
\hline 13 & $b+d$ & $b+d$ & Yes \\
\hline 14 & $b+d$ & $b+d$ & Yes \\
\hline 15 & $b+d$ & $b+d$ & Yes \\
\hline 16 & $c+d$ & $c+d$ & Yes \\
\hline 17 & $c+d$ & $c+d$ & Yes \\
\hline 18 & $c+d$ & $c+d$ & Yes \\
\hline 19 & $a+b+c$ & $a+b+c$ & Yes \\
\hline 20 & $a+b+c$ & $a+b+c$ & Yes \\
\hline 21 & $a+b+c$ & $a+b+c$ & Yes \\
\hline 22 & $a+c+d$ & $a+c+d$ & Yes \\
\hline 23 & $a+c+d$ & $a+c+d$ & Yes \\
\hline 24 & $a+c+d$ & $a+c+d$ & Yes \\
\hline 25 & $b+c+d$ & $b+c+d$ & Yes \\
\hline 26 & $b+c+d$ & $b+c+d$ & Yes \\
\hline 27 & $b+c+d$ & $b+c+d$ & Yes \\
\hline 28 & $a+b+c+d$ & $a+b+c+d$ & Yes \\
\hline 29 & $a+b+c+d$ & $a+b+c+d$ & Yes \\
\hline 30 & $a+b+c+d$ & $a+b+c+d$ & Yes \\
\hline
\end{tabular}


Table S6 SVM results for identification of unknown samples within the reference set for seven different cells using PT2, PT3 and PT5.

\begin{tabular}{cccc}
\hline No. & True ID & Identified as & $\begin{array}{c}\text { SVM Correct } \\
\text { Identification }\end{array}$ \\
\hline 1 & Cervical & Cervical & Yes \\
2 & Cervical & Cervical & Yes \\
3 & Cervical & Cervical & Yes \\
4 & Breast & Breast & Yes \\
5 & Breast & Breast & Yes \\
6 & Breast & Breast & Yes \\
7 & Neuroblastoma & Neuroblastoma & Yes \\
8 & Neuroblastoma & Neuroblastoma & Yes \\
9 & Neuroblastoma & Neuroblastoma & Yes \\
10 & Lung & Lung & Yes \\
11 & Lung & Lung & Yes \\
12 & Lung & Lung & Yes \\
13 & Umbilical Vein Endothelial & Umbilical Vein Endothelial & Yes \\
14 & Umbilical Vein Endothelial & Umbilical Vein Endothelial & Yes \\
15 & Umbilical Vein Endothelial & Umbilical Vein Endothelial & Yes \\
16 & Renal Epithelial & Renal Epithelial & Yes \\
17 & Renal Epithelial & Renal Epithelial & Yes \\
18 & Renal Epithelial & Renal Epithelial & Yes \\
19 & Cholangiocarcinoma & Cholangiocarcinoma & Yes \\
20 & Cholangiocarcinoma & Cholangiocarcinoma & Yes \\
21 & Cholangiocarcinoma & Cholangiocarcinoma & Yes \\
\hline
\end{tabular}

Table S7 SVM results for identification of unknown samples within the reference set for seven different cells using PT2 and PT3.

\begin{tabular}{cccc}
\hline No. & True ID & Identified as & $\begin{array}{c}\text { SVM Correct } \\
\text { Identification }\end{array}$ \\
\hline 1 & Cervical & Cervical & Yes \\
2 & Cervical & Cervical & Yes \\
3 & Cervical & Cervical & Yes \\
4 & Breast & Breast & Yes \\
5 & Breast & Breast & Yes \\
6 & Breast & Breast & Yes \\
7 & Neuroblastoma & Neuroblastoma & Yes \\
8 & Neuroblastoma & Neuroblastoma & Yes \\
9 & Neuroblastoma & Neuroblastoma & Yes \\
10 & Lung & Lung & Yes \\
11 & Lung & Lung & Yes \\
12 & Lung & Lung & Yes \\
13 & Umbilical Vein Endothelial & Umbilical Vein Endothelial & Yes \\
14 & Umbilical Vein Endothelial & Breast & No \\
15 & Umbilical Vein Endothelial & Umbilical Vein Endothelial & Yes \\
16 & Renal Epithelial & Renal Epithelial & Yes \\
17 & Renal Epithelial & Renal Epithelial & Yes \\
18 & Renal Epithelial & Renal Epithelial & Yes \\
19 & Cholangiocarcinoma & Cholangiocarcinoma & Yes \\
20 & Cholangiocarcinoma & Cholangiocarcinoma & Yes \\
21 & Cholangiocarcinoma & Cholangiocarcinoma & Yes \\
\hline & & & \\
& & &
\end{tabular}




\section{References}

[1] Chen, W.; Li, Q.; Zheng, W.; Hu, F.; Zhang, G.; Wang, Z.; Zhang, D.; Jiang, X., Identification of bacteria in water by a fluorescent array. Angew. Chem. Int. Ed. 2014, 53, 13734-13739.

[2] Ma, Y.; Wang, H.; Su, S.; Chen, Y.; Li, Y.; Wang, X.; Wang, Z., A red mitochondria-targeted AIEgen for visualizing $\mathrm{H}_{2} \mathrm{~S}$ in living cells and tumours. Analyst 2019, 144, 3381-3388. 